\title{
Congress of Neurological Surgeons Systematic Review and Evidence-Based Guidelines Update on the Role of Cytotoxic Chemotherapy and Other Cytotoxic Therapies in the Management of Progressive Glioblastoma in Adults
}

Isabelle M. Germano ( $\nabla$ isabelle.germano@mountsinai.org )

Mount Sinai School of Medicine https://orcid.org/0000-0002-3992-373X

Mateo Ziu

Inova Fairfax Medical Campus: Inova Fairfax Hospital

patrick wen

Harvard Medical School

david ryan ormond

CU Denver: University of Colorado Denver

jeff olson

Emory University

\section{Research Article}

Keywords: chemotherapy, fotemustine, GBM, oncolytic virus, progressive, temozolomide, TOCA511, TTF

Posted Date: September 9th, 2021

DOI: https://doi.org/10.21203/rs.3.rs-827194/v1

License: (c) (i) This work is licensed under a Creative Commons Attribution 4.0 International License. Read Full License

Version of Record: A version of this preprint was published at Journal of Neuro-Oncology on February 23rd, 2022. See the published version at https://doi.org/10.1007/s11060-021-03900-w. 


\section{Abstract}

\section{Target population}

These recommendations apply to adult patients diagnosed with progressive glioblastoma (pGBM).

Question (Q1):

In adult patients with pGBM does the use of temozolomide (TMZ) with alternative dosing or the use of TMZ in combination with other cytotoxic treatments result in increased overall survival compared to other chemotherapy?

\section{Recommendation:}

Level III: Adult patients with pGBM might derive benefit in treatment with TMZ especially those who progress after more than 5 months of TMZ-treatment free interval.

Level III: Combination of TMZ with other cytotoxic agents such as nitrosourea, cisplatin, electrohypothermia, or tamoxifen is not suggested in adult patients with pGBM as a stand-alone therapy.

There is insufficient data to make a recommendation about which alternative TMZ dosing provides the best benefits.

\section{Question (Q2):}

In adult patients with pGBM does the use of systemic or in situ nitrosourea result in increased overall survival compared to other chemotherapy?

\section{Recommendation:}

Level III: In the setting of pGBM, fotemustine is suggested in elderly patients with methylated MGMT promoter status. There is insufficient evidence to compare fotemustine to other nitrosoureas.

There is insufficient evidence to make a suggestion about the use of in situ nitrosourea in patients with pGBM who underwent the Stupp regimen.

\section{Question (Q3):}

In adult patients with $p G B M$ does the use of platinum compounds and topoisomerase result in increased survival compared to other chemotherapy?

\section{Recommendation:}

Level III: Other chemotherapy including platinum compounds and topoisomerase inhibitors are not suggested to be used in adult patients with pGBM.

Level III: Other cytotoxic therapies like perillyl acohol and ketogenic diet are not suggested for use in adult patients with pGBM as a stand-alone therapy.

\section{Question (Q4):}

In adult patients with pGBM does the use of tumor treating field (TTF) result in increased overall survival compared to chemotherapy? 


\section{Recommendation:}

Level III: The use of TTF with other chemotherapy may be considered when treating adult patients with pGBM.

There is insufficient evidence to recommend TTF to increase overall survival in adult patients with pGBM.

\section{Question (Q5):}

In adult patients with $p G B M$ does the use of oncolytic virotherapy result in increased survival compared to chemotherapy?

\section{Recommendation:}

Level III: Oncolytic virotherapy is not suggested in patients with pGBM.

\section{Introduction}

\section{Rationale}

Chemotherapy and other cytotoxic therapies play a key role in the management of patients with progressive glioblastoma multiforme (pGBM). The term "progressive" has been chosen as preferential, consistent with the previous guidelines, to underscore the reality that few or no GBM are truly eradicated with the initial therapy and evidence of new disease represents progression of the original disease.

In the published literature the term "recurrent GBM" is often encounter. Therefore, in this chapter these terms are used interchangeably. The previous guidelines focused on review of the published peer- reviewed English literature for the period January 1, 1990 to June 30, 2012 on cytotoxic chemotherapy used for adult patients with pGBM. In recent years, cytotoxic therapies other than chemotherapy has been used to treat adult patients with pGBM.

\section{Objectives}

The purpose of this update is twofold. First, we seek to review new literature on cytotoxic chemotherapy for patients with pGBM since the last set of guidelines [1]. Second, we want to include cytotoxic therapies other than chemotherapy used for adult patients with pGBM, such us oncolytic viruses, tumor treating fields (TTF), and others. Because these topics were not covered in the previous guidelines, their literature search spanned over the last two decades.

\section{Summary of Prior Recommendations}

In the previously published guidelines on the chemotherapeutic management of progressive GBM [1], temozolomide (TMZ) reached level II recommendation compared to procarbazine in patients with first relapse of GBM after receiving nitrosurea or no prior cytotoxic therapy based on one prospective randomize phase II study [2]. BCNU-impregnated biodegradable polymers were recommended as level II based upon one study [3] in patients treated prior to the Stupp protocol $[4,5]$. A Level III recommendation was given to nitrosoureas, topoisomerase inhibitors, and platinum compounds.

\section{Methods}

\section{Writing Group and Question Establishment}


The evidence-based clinical practice guideline taskforce members and the Joint Tumor Section of the American Association of Neurological Surgeons (AANS) and the Congress of Neurological Surgeons (CNS) have prioritized an update of the guidelines for management of progressive glioblastoma (GBM). The writers represent a multi-disciplinary panel of clinical experts encompassing neurosurgery, neuro-oncology, and radiation oncology. Together, they were recruited to develop this update on the evidence-based practice guidelines for progressive diagnosed GBM in adults. The methodology and findings of the previous guidelines were reviewed and additional questions were developed to incorporate recent literature addressing practice patterns in management of pGBM patients.

\section{Literature Search}

The following electronic databases were searched from July 1, 2012 to March 31, 2019: PubMed and Cochrane Database of Systematic Reviews using relevant MeSH and non-MeSH terms. The search strategy used for PubMed is below summarized. This was then adapted for Cochrane and EMBASE.

For Search\#1: ((((progress* OR recurren* OR relaps*) AND (glioma OR glioblastoma) AND chemotherapy AND (survival OR mortality) AND adult)) AND English [Lang]) AND "2012/07/01"[PDAT]: "2019/03/31"[PDAT]

For Search\#2: The search strategy for PubMed was:((((progress* OR recurren* OR relaps*) AND (glioma OR glioblastoma) AND chemotherapy AND quality of life AND adult))) AND English [Lang]) AND "2012/07/01"[PDAT] : "2019/03/31"[PDAT]. .

For Search \#3 the electronic databases were searched from January 1, 2000 to March 31, 2019. This was longer than the period for the above two searches because the previous guidelines did not address the topic of tumor treating fields and oncolytic viral therapy. The relevant MeSH and non-MeSH terms were used, including the following (progress* OR recurren* OR relaps*) AND (glioma OR glioblastoma) AND (TTF* OR tumor-treating- field* OR oncolytic virus* OR vocimagene amiretrorepvec* OR TOCA511*) AND (quality of life OR survival OR mortality

\section{Study Selection and Eligibility Criteria}

To be included in the guideline, a publication had to meet the following inclusion criteria:

- Peer-reviewed publications

- Clinical studies in patients with progressive GBM / high grade glioma when GBM results were reported separate from other HGG

- Each study reporting on at least five or more subjects

- Adult patients (>18 years of age). Studies with mixed adult and child populations were included if the adult cohorts could be isolated and analyzed separately

- Publications written in English

The search criteria were developed and performed by two independent reviewers.

Citations were independently reviewed and included if they met the a prioricriteria for relevance. No discrepancies in study eligibility were noted. Corresponding full-text PDFs were obtained for all citations meeting the criteria and reviewed. Data was extracted by the first reviewer and verified by another, all of which were compiled into evidence tables. The tables and data were reviewed by all the authors. Articles not meeting the selection criteria were removed.

\section{Data Collection Process}


Our search criteria yielded a total of 1665 publications, which were reviewed by the authors independently. Among these, 87 studies met the eligibility criteria and were further screened. Those abstracts that met with the selection criteria mentioned above were retrieved in full text form.

Corresponding full-text PDFs were obtained for all citations meeting the criteria and reviewed. Forty of the 87 studies met all outlined selection criteria and specifically focused on cytotoxic therapies for progressive GBM (Fig. 1). The adherence to the selection criteria were confirmed. Data were extracted by the first reviewer and verified by another, all of which were compiled into evidence tables. The tables and data were reviewed by all the authors. Articles not meeting the selection criteria were removed.

\section{Assessment for Risk of Bias}

Our search generated a list of abstracts, which were screened, and those articles that addressed our identified questions underwent full independent review by the authors. Reviewers were critical in their assessment, specifically in regard to trial design, such as randomization of treatment, blindness, prospective character, size of study population, baseline characteristics between study groups which could account for survivorship bias, selection bias, and appropriate statistical analyses of reported data.

\section{Classification of Evidence and Recommendation Levels}

Each reviewer independently determined the strength of the evidence, classified the level of evidence according to the criteria described in the Introduction section. For each article, a level of recommendation was achieved. Level I was reserved for well-designed, prospective, randomized and controlled studies with clear mechanisms to limit bias. Level II recommendations described studies that were randomized and controlled studies, but with design flaws leading to potential bias and limiting the paper's conclusions, non-randomized cohort studies, and case-control studies. Level III recommendations were reserved for single surgeon, single institutional case series, comparative studies with historical control, and randomized studies with significant flaws related to studies with limited power and compromised statistical analysis.

Additional information on study classification and recommendation development can be found at https://www.cns.org/guidelines/guideline-procedures-/guideline-development methodology.

\section{Results}

Question (Q1): In adult patients with $p G B M$ does the use of temozolomide (TMZ) with alternative dosing or the use $T M Z$ in combination with other cytotoxic treatments result in increased overall survival compared to other chemotherapy?

Eleven eligible studies examined the use of temozolomide for the treatment of pGBM and were included in this analysis. Table 1A summarizes the 6 studies [6-11] that examined the use of TMZ at doses different than what published by Stupp et al [4]. Table 1B summarizes 6 studies [12-17] reporting on the use of TMZ in combination with other cytotoxic agents. All of these studies provided Class III evidence.

\section{Metronomic Temozolomide $(\underline{T M Z})$.}

Wong et al [6] conducted a very small phase I trial of low dose metronomic TMZ (25- 50mg/m2 daily) in 9 recurrent malignant glioma patients including 6 with glioblastoma. Response rates were not mentioned. The median PFS was 
3.1 months and median OS was 12.5 months. The authors concluded that metronomic temozolomide had efficacy in recurrent malignant gliomas but there were too few patients for any meaningful conclusions.

Omuro et al [9] conducted a phase II trial of metronomic temozolomide (50mg/m2 daily) in 37 patients with heavily pretreated glioblastoma patients, including $49 \%$ with prior bevacizumab. $11 \%$ of patients experienced a partial response (PR) and 25\% experienced stable disease (clinical benefit 36\%). The 6-month progression-free survival (PFS6) was $19 \%$. Median overall survival (OS) was 7 months Patients with previous bevacizumab exposure survived significantly less than bevacizumab-naive patients (median overall survival: 4.3 months vs 13 months; hazard ratio = 3.2; $P=.001)$, but those patients had lower KPS $(P=.04)$ and higher number of recurrences $(P<.0001)$. The authors concluded that in this heavily pretreated population with nearly half of patients having failed bevacizumab, the regimen had some activity and deserved further evaluation.

\section{Dose Dense Temozolomide ( $\underline{\text { dd-TMZ). }}$}

Han et al [8] treated 60 patients with recurrent high-grade glioma in a phase II single arm prospective trial with 150 $\mathrm{mg} / \mathrm{m} 2$ of dose dense temozolomide(TMZ) given on days $1-7$ and day $15-21$ of a 28 days cycle for 12 cycles after recurrence. Forty patients from the cohort had recurrent glioblastoma (GBM). Primary end point was progression-free survival at 6 months to be better than the historical control of recurrent glioma participants in other phase II trials (PFS$610 \%$ for GBM). In the current study, PFS- 6 achieved was $10 \%$ and median OS was $21.6 \%$. They concluded that dosedense TMZ at recurrence is feasible; however, the primary efficacy endpoint for these patients was not achieved. This study was classified as class III evidence due to the design and lack of control arm.

Norden et al [11] conducted a multicenter phase II trial of dose dense temozolomide $75-100 \mathrm{mg} / \mathrm{m} 2 /$ day) for 21 days of every 28 day cycle in 58 recurrent glioblastoma patients. 13\% of patients experienced a PR and PFS- 6 was only $11 \%$. MGMT methylated patients had longer OS but not PFS. The authors concluded that dose-dense temozolomide on this schedule was safe in recurrent glioblastoma patients but the efficacy was marginal and predictive biomarkers were needed.

Archavlis et al [10] in this retrospective two- center study, the median survival and complication rate of 111 pGBM patients who received dose dense Temozolomide or re-operation or $f$ interstitial high dose rate brachytherapy (HDRBRT) at recurrence were compared. The HDR-BRT group did significantly better than both the reoperation $(p<0.05)$ and the ddTMZ groups $(p<0.05)$. Moderate to severe complications were reported in the HDR-BRT group. The Authors concluded that the survival benefit of ddTMZ is lower than HDR-BRT. This study was classified as class III evidence due to the design.

Other Temozolomide (TMZ) dosing.

Van Vugt et al [7] conducted a small retrospective study involving 15 high-grade glioma patients including 13 recurrent glioblastoma patients who had progressed on temozolomide who were treated with $\mathbf{3}$ days on/11 days off temozolomide regimen $(300 \mathrm{mg} / \mathrm{m} 2)$. Toxicity of the regimen was comparable to other temozolomide regimen. The objective response rate (ORR) was 7\%, median PFS was 4.1 months, PFS- 6 was $25 \%$ and median 0 s was 13.8 months. Although the authors indicate that the regimen was tolerable and warranted further evaluation the small number of patients makes it difficult to know if this regimen is any different from other temozolomide regimens.

\section{$\underline{\text { Temozolomide }}(\underline{\mathrm{TMZ}}) \underline{\text { in combination with other cytotoxic agents. }}$}

Roussakow et al [12] conducted a retrospective review of 54 recurrent glioblastoma patients treated with dose - dense TMZ (21/28 day regimen) with modulated electrohypothermia and compared the data to those of patients treated on 
trials with dose-dense TMZ. The objective response rate (ORR) was $20 \%$; $33 \%$ had stable disease (SD) and median OS was 7.7 months. The authors concluded that modulated electrohyperthermia significantly improved survival of patients receiving the dose dense TMZ using 21/28 days regimen. Economic evaluation suggested that the therapy was cost-effective. However, this was a retrospective and somewhat unconventional analysis. Despite claims of efficacy the results of the treatment group were not significantly different from comparator group. These results will require validation in prospective randomized studies.

Aoki et al [13] reported a phase I/II trial of 49 patients with malignant glioma treated with combination of TMZ and ACNU (nimustine). There were 40 patients unrolled in the phase II trial including one cohort from the phase I trial. For patients with GBM ( $n=33)$, median PFS was 10 weeks and PFS at 6 and 12 months after this treatment were $21 \%$ and $6 \%$ respectively. Median OS was 10.3 months for these patients. OS at 6 and 12 months after this treatment were $74 \%$ and $44 \%$, respectively. On multivariate analysis treatment response or disease stabilization attained with this therapy was predictive of OS. The use of combination of TMZ and ACNU at progression according to the authors showed equal or non-inferior efficacy in PFS with moderate myelotoxicity with promising results of OS. The authors do not define their conclusions for GBM patients only, but for all their patient population. Hence it is difficult to have any conclusions for pGBM from this study. This study was classified as a class III due to lack of comparison arm.

Wang et al [14] conducted a phase II study of continuous TMZ (50mg/m2 daily) with cisplatin (40, 30, and 30mg administered on days 1, 2, and 3) in 27 patients with pGBM. There was moderate toxicity. The objective response rate (ORR) was 22.2\%, median time-to-progression (TTP) was 23 weeks, the PFS-6 was 37\%, 12-month progression-free survival (PFS12) was $11.1 \%$ and median OS was 50 weeks. The authors concluded that cisplatin with continuous dose-intense regimen of temozolomide had an acceptable level of toxicity and showed activity in patients with recurrent glioblastoma. This regimen showed more activity than most other regimens for recurrent glioblastomas. Limitations of the study include lack of reporting on pseudo-progression. Furthermore, the study had only one group and no comparison group to make definite conclusions regarding the benefit of the addition of cisplatin to TMZ.

Reynes et al [15] conducted a phase II study of metronomic temozolomide ( $50 \mathrm{mg} / \mathrm{m} 2$ daily) with irinotecan (100mg/m2 on days 8 and 22 of 28 days cycles) in 27 recurrent glioblastoma patients at first relapse. No responses were observed. Stable disease was seen in $37.5 \%$ of patients. PFS- 6 was $20.8 \%$ and median PFS was 11.6 weeks. Grade 3/4 adverse events included lymphopenia (15\%), fatigue, diarrhea and febrile neutropenia (3.7\% each), lymphopenia, neutropenia, and nausea/vomiting (11.1\% each). One patient died from pulmonary embolism. The authors concluded that the regimen is feasible but failed to improve on the results obtained with other second-line therapies in recurrent glioblastoma.

Di Cristofori et al [16], reported on a prospective single-arm single institution study in 32 patients using dose-dense TMZ (75 - $150 \mathrm{mg} / \mathrm{m} 2)$ one week on and one week off plus daily tamoxifen ( $80 \mathrm{mg} / \mathrm{m} 2)$. OS was 17.5 months and time to progression after recurrence was 7 months. There was minimal toxicity. The authors concluded that combinatorial administration of tamoxifen and dose-dense TMZ was well tolerated and potentially effective. This study was small and without a control arm as such classified as class III evidence.

Franceschi et al [17] reported a retrospective review of 106 patients with recurrent GBM, comparing standard dosing schedule of temozolomide ( $n=70$ ) with standard schedule nitrosourea chemotherapy (fotemustine and lomustine) $(n=36)$. Progression Free Survival (PFS) was 7.2 and 5.1 months in TMZ and nitrosourea group respectively $(p=0.009)$. When considering patients in the TMZ group with treatment free interval (TFI) $>5$ months, PFS was 8.1 months and 5.8 months for patients treated with TMZ or nitrosourea $(p=0.020)$. No difference in PFS was noticed between the two groups for patients with TFI of less than 5 months. Median OS was 14.2 months and was significantly longer for patients on TMZ than those on nitrosourea (15.2 months vs 11.5 months respectively; $\mathrm{p}=0.020$ ). Patients with TFI $>5$ 
months derived the largest OS benefits from TMZ rechallenge where the median OS was 17.7 months when compared to 11.6 months with patients that received nitrosourea therapy $(p=0.014)$. They concluded that TMZ re-challenge is a treatment options for patients with TFI > 5 months irrespective of MGMT methylation status. This was a retrospective study and as such classified as class III evidence.

\section{Q1-Synthesis}

Since the initial guideline publication [1], attempts to improve the dosage of TMZ as described in the Stupp regimen [2005] have continued. These include among others increased TMZ dosage, known as dose-dense TMZ regimen (ddTMZ) and/or daily TMZ, aka metronomic. The rationale for such approach is that prolonged exposure to higher cumulative doses of TMZ could sensitize tumors to the alkylating damage, with toxicity as a natural limiter for such dose escalation.

Our analysis found a lack of adequately powered randomized studies evaluating the role of different TMZ schedules alone or in combination with other drugs in patients with pGBM. Most of the studies are either single arm phase II studies or retrospective studies, providing Class III evidence. None of the studies shows definite benefit of alternative TMZ dosing compared to the conventional TMZ regimen.

There is Class III evidence supporting Level III recommendation that in patients with pGBM, TMZ may be considered, especially in patients that progress after more than 5 months of a TMZ-treatment free interval based on a Class II study [11]. Since, none of these treatment regimens have been compared with each other, a definitive recommendation on the best treatment regimen cannot be made.

Combination of TMZ with other cytotoxic agents such as nitrosourea, cisplatin, electrohypothermia, or tamoxifen did not provide any additional benefit than TMZ alone.

Question (Q2): In adult patients with pGBM does the use of systemic or in situ nistrosourea result in increased overall survival compared to other chemotherapy?

There were 8 studies eligible which examined the use of systemic or in situ nitrosureas for the treatment of pGBM eligible and were included in this analysis. Table 2 summarizes the 8 studies [17-24] that examined the use systemic or in situ nitrosoureas for the treatment of pGBM. These studies provided Class III evidence.

\section{Fotemustine}

Marinelli et al [18] reported the results of a Phase I/II single arm trial of fotemustine in 37 patients with recurrent GBM. Fotemustine was administered IV at doses of $120 \mathrm{mg} / \mathrm{m} 2$ in 31 patients and $140 \mathrm{mg} / \mathrm{m} 2$ in 6 patients every 2 weeks for up to 1 year or until disease progression or intolerable toxicity occurred. Median PFS was 12.1 weeks and OS was 19.7 weeks. Grades 3 and 4 thrombocytopenia occurred in 4 of 6 patients treated with higher dose and in 3 of 31 patients treated with the lower dose. The authors concluded that fotemustine can be safely administered at 120 $\mathrm{mg} / \mathrm{m} 2$.

Perez-Segura et al [20] reported a retrospective study of 84 patients with recurrent GBM and 30 with other high-grade gliomas treated with fotemustine given with different schedules at first and second recurrence. They did not find any statistically significant difference on survival between different schedules used. They concluded that fotemustine is a safe and has comparable activity with other available options. OS at 12 months was $24.7 \%$ and overall PFS was 3 months. We were unable to separate the results for patients with GBM and anaplastic gliomas. 
Lombardi et al [21] reported the results of a retrospective review of 44 patients 65 years of age and older with recurrent GBM treated with alternative fotemustine monotherapy at the time of recurrence $(80 \mathrm{mg} / \mathrm{m} 2$ every 2 weeks for 5 consecutive administrations and then every 4 weeks as maintenance. PFS and OS after recurrence was respectively 4.1 months and 7 months. Patients with MGMT promoter methylation had longer PFS and OS 4.5 versus 2.9 months $(p=0.001)$ and 9.2 versus 4.5 months $(p=0.04)$ respectively. They concluded that elderly patients with methylated MGMT who relapse after TMZ may be best candidates for this therapy. As a retrospective study this was classified as class III evidence.

Santoni et al [24] retrospectively reviewed 65 elderly glioblastoma patients ( $>65$ years) patients who were treated with fotemustineat $70-100 \mathrm{mg} / \mathrm{m} 2$ weekly for 3 weeks and then every 3 weeks. The treatment was reasonably well tolerated. $15.3 \%$ of patients experienced grade 3-4 thrombocytopenia and $9.2 \%$ Grade 3-4 neutropenia. There was some evidence of efficacy with $1.5 \% \mathrm{CR}, 18.5 \% \mathrm{PR}$, and $27.7 \%$ SD. The PFS6 was $35.4 \%$ and OS was 7.1 months. The authors concluded fotemustine was a valuable therapeutic option for elderly glioblastoma patients with a safe toxicity profile. However, the retrospective nature of the study limits firm conclusions.

De Felice et al [25] conducted a very small prospective single-arm single institution study of 8 patients treated fotemustine (induction with $100 \mathrm{mg} / \mathrm{m} 2$ weekly for 3 weeks followed 5 weeks later by a maintenance dose of 75 $\mathrm{mg} / \mathrm{m} 2$ every 3 weeks) and reported a median OS of 7.5 months from recurrence without hematologic toxicity. They concluded that maintenance with low dose of fotemustine could be considered for patients with recurrent GBM. This is a single arm study of only 8 patients and as such was classified as a class III study.

\section{Other nitrosoureas}

Carvalho et al [22] reported a study of 60 patients with recurrent GBM that were treated with procarbazine, lomustine $(\mathrm{CCNU})$ and vincristine PCV $(\mathrm{n}=19)$ and bevacizumab/irinotecan $(\mathrm{BI})(\mathrm{n}=41)$. The median PFS was 3 months and 5 months respectively and median OS was 5 months and 9 months respectively. The PCV group had worse toxicity profile. At one year the percentage of patients alive was greater for the BI cohort. They concluded that $\mathrm{BI}$ therapy is a valuable option in recurrent GBM patients. Because of the retrospective nature of the study this was classified as class III evidence.

\section{Systemic and in situ carmustine (BCNU).}

Mack et al [23] conducted a retrospective review of 15 recurrent malignant glioma patients (12 with glioblastoma) treated with systemic BCNU (130-150 mg/m2, day 1/42) and VM26 (45-60 mg/m2, days 1-3/42). The median PFS was 2 months and the median OS was 4 months. Two patients (14\%) developed grade 3 and/or 4 hematologic toxicity. The authors concluded that the regimen was not beneficial.

Klein et al [19] retrospectively reviewed a cohort of 79 patients with recurrent GBM and methylated MGMT promoter. Twenty-four patients were older than 65 years of age and 39 younger than 65 years of age were treated with BCNU wafer implantation in the surgical bed while 16 patients older than 65 years of age did not receive BCNU implantation. The majority of patients in all groups received systemic TMZ and very few received ACNU (nimustine), CCNU (lomustine), bevacizumab and irinotecan or a combination of these. Median PFS was 9.2 months in the elderly BCNU group and 7.4 months in the non- BCNU group ( $p=0.34)$. Median PFS was 6.7 months in younger group. The OS was respectively 17.2 months and 15.9 months $(p=0.35)$ for elderly groups with or without BCNU implantation. The OS was 19 months for the younger patients. Survival depending on the MGMT methylation status did not differ significantly between all groups as well. There was a higher incidence of seizures and pneumonia in older BCNU group however this was not significantly different between the groups. The authors concluded that BCNU wafer implantation is a 
reasonable safe treatment for patients older than 65 years of age and although there are higher complications, the tradeoff is still favorable. We classified this study as class III because of the retrospective nature. Furthermore, there was no statistically significant difference between groups in terms of survival and complications. A trend toward increased incidence of seizures was noted in the group of patients that received BCNU wafers.

\section{Q2-Synthesis}

Six phase II or retrospective studies providing Class III evidence using the systemic nitrosourea fotemustine appear to show modest activity comparable to other nitrosourea in adult patients with pGBM, including in elderly patients. Patients that benefited the most from use of fotemustine appear to be the elderly patients with methylated MGMT promoter status. One study showed some benefit of the combination of bevacizumab and irinotecan but the contribution of the irinotecan component cannot be determined.

The use of in situ BCNU wafers, assessed in one study, showed that in patients treated with Stupp regiment, did not result in statistically significant increase in OS when used in adult patients with pGBM with or without additional undergoing systemic chemotherapy. Therefore, there is insufficient evidence to make a suggestion about the use of in situ nitrosourea in patients with pGBM who underwent the Stupp regimen. Prior to the Stupp regimen, the previous edition of these guideline, based one a single Class II study [3] provided Level II recommendation that in situ BCNU is indicated in patients with pGBM. In that study, although patients showed a modest increase in OS, they sustained a significantly higher complication rate.

To complete the discussion, it must be noted that Lomustine, known as CCNU (chloroethyl-cyclohexyl- nitrosourea), an oral alkylating agent of the nitrosourea family is often used in clinical practice and increasingly used as a control arm in clinical trials testing immune-therapy (these will be reviewed in another section of this guideline). Although this review was not able to identify Class II evidence about this drug, it is gaining a standard-of-care position in the setting of p GBM in Europe, where bevacizumab is not approved, in the EANO guideline [25] and also in the Adaptive Global Innovative Learning Environment for Glioblastoma (AGILE) consortium [26].

Question (Q3): In adult patients with pGBM does the use of cytotoxic therapies other than TMZ and nitrosurea result in increased survival compared to other available chemotherapy?

There were 8 studies eligible which examined the use of systemic chemotherapy other than TMZ or nitrosureas for the treatment of pGBM eligible and were included in this analysis. These studies summarized in Table 3 provided Class III evidence [27-35].

\section{Platinum compounds}

Roci et al [31] conducted a retrospective study of 48 high-grade glioma patients including 42 patients with recurrent glioblastoma treated with carboplatin (AUC 5-7) or cisplatin $70 \mathrm{mg} / \mathrm{m} 2$ every 4 weeks. $28 \%$ of patients had at least a minor response; $49 \%$ had stable disease. PFS6 was 18\% and median OS was 7 months. The authors concluded that single-agent carboplatin/cisplatin had modest activity in patients with recurrent high-grade glioma previously treated with one line of chemotherapy but the activity was actually minimal.

Tonder et al [33] conducted a retrospective review of 12 heavily pretreated recurrent high grade glioma patients including 8 glioblastoma patients treated with carboplatin $(240 \mathrm{mg} / \mathrm{m} 2$ on day 1$)$ and etoposide $(100 \mathrm{mg} / \mathrm{m} 2$ on days 2 and 3) every 4 weeks. Significant toxicity was observed with grade $3-4$ hematologic toxicity in $67 \%$ of patients. The median PFS was 2.5 months and the PFS6 was $0 \%$. The authors concluded that carboplatin in combination with etoposide had an unfavorable risk-benefit profile in heavily pre-treated glioma patients. 
Hu et al [35] reported a phase II study of 29 patients with recurrent GBM treated with gimatecan, a lipophilic oral camptothecin analogue with preclinical activity in glioma models. Treatment regimen was $1 \mathrm{mg} / \mathrm{m} 2 /$ day for five consecutive days during 28 day cycle for 12 cycles. Of the 25 patients that the authors could analyze, only 3 (12\%) reached PFS-6. The authors concluded that PFS-6 patients treated with gimatecan at the time of recurrence was no significantly better than the historical PFS-6 for these patients.

\section{Others: Perillyl Alcohol and Ketogenic Diet}

Da Fonseca et al [34] reported a single center phase I/II trial on 155 pGBM patients using perillyl alcohol (POH) inhalation schedule 4-times daily started with $66.7 \mathrm{mg} /$ dose; $266 \mathrm{mg} /$ day and escalated up to $133.4 \mathrm{mg} / \mathrm{dose}$. POH caused occasional nose soreness (5/198) and rare nosebleed (2/198). A 6-month progression-free survival rate is cited at $48 \%$ for glioblastoma but includes partial responses and stable disease. The survival rate after $24 \mathrm{months}$ of $\mathrm{POH}$ treatment was $6.2 \%$ for primary GBM $(n=144)$, and 63\% for secondary GBM $(n=11)$. Partial responses were not separated from stable disease. This manuscript is assessed as providing class III data because it is a phase I/II study. The $48 \%$ response rate for glioblastoma at 6 months, though initially impressive sounding, includes stable disease. As this is a somewhat nontraditional definition of efficacy, a formal recommendation regarding the use of $\mathrm{POH}$ is not warranted.

In a phase I open-label, prospective, single-arm study Rieger et al [32] treated 20 pGBM patients with ketogenic diet, restricting carbohydrate intake to $60 \mathrm{~g} /$ day. Feasibility was the primary endpoint, secondary endpoints included the percentage of patients reaching urinary ketosis, progression-free survival (PFS) and overall survival (OS). No serious adverse events attributed to the diet were observed. Urine ketosis was achieved at least once in 12 of 13 (92\%) evaluable patients. Median PFS of all patients was 5 weeks (range, 3-13), median survival from enrollment was 32 weeks. One patient achieved a minor response and two patients had stable disease after 6 weeks. All pts had progression on diet alone. Three patients (15\%) discontinued the diet for poor tolerability. This study suggests that ketogenic diet alone is not an effective treatment for pGBM patients.

\section{Other cytotoxic therapy.}

Fiorentini et al [28] Multicenter retrospective controlled study on 28 pts with pGBM treated with modulated electrohyperthermia ( $\mathrm{mEHT}$ ) which combines heat therapy and electric field compared to best supportive care (BSC). Tumor response at the 3-month follow-up was observed in $29 \%$ of pGBM treated with mEHT compared to $4 \%$ BSC. The median OS for mEHT was 14 months (range 2-108 months). The authors suggested that mEHT may have a promising role in the treatment of pGBM but the small not-controlled nature of the study makes it hard to form any definitive conclusions.

Silvani et al [29] conducted a phase II trial of ortataxel $(75 \mathrm{mg} / \mathrm{m} 2$ every 3 weeks) in 40 recurrent glioblastoma patients. PFS-6 was only $11.4 \%$. $13.2 \%$ of patients had grade III/IV neutropenia and hepatotoxicity and $15.8 \%$ had grade III/IV leucopenia. The authors concluded that ortataxel failed to demonstrate significant activity in recurrent GBM patients.

Ja et al [30] report on 19 patients with pGBM in a single center prospective phase I trial treated with escalating doses of retinoic acid naphthalene triazole (RANT). Of the 19 treated patients, 5 achieved minor response, 6 remained in stable conditions, none achieve a partial or complete response. Skin erythema, cheilitis and conjunctivitis was observed only at the highest dose $100 \mathrm{mg} / \mathrm{sqm}$. This study suggests that RANT toxicity is tolerable with possibly modest clinical activity. 


\section{Q3-Synthesis}

There is Class III evidence that the use of chemotherapy other than TMZ, including platinum compounds and topoisomerase inhibitors does not result in significant clinical benefit in patients with pGBM. Therefore, these chemotherapies are suggested against being used in patients with pGBM. Current Class III evidence supports that other cytotoxic therapies like perillyl alcohol or ketogenic diet when used alone are suggested against being used in patients with $\mathrm{pGBM}$.

Question (Q4): In adult patients with pGBM does the use of tumor treating field (TTF) result in increased overall survival compared to chemotherapy?

Tumor-treating fields (TTF) is an antimitotic treatment modality that interferes with glioblastoma cell division and organelle assembly by delivering low-intensity alternating electric fields to the tumor Tumor- treating fields (TTF) are an antimitotic treatment that selectively affects dividing GBM cells by delivering low-intensity, intermediate-frequency (200 $\mathrm{kHz}$ ) alternating electric fields. These cause misalignment of microtubules subunits in the mitotic spindle during the metaphase to anaphase transition and by dielectrophoretic movement of intracellular macromolecules and organelles during the telophase[36-37]. The treatment is delivered using a device consisting of transducer arrays applied to the patient's scalp and then connected to a portable battery. The Novocure Optune Device, that allows TTF treatment, was given FDA approval for treatment of recurrent GBM in 2011. Table 4 summarizes the studies using TTF for treatment of adult patients with pGBM. In 4 of these, TTF were used alone and in 2 in combination with other cytotoxic chemotherapy [38-43].

Lu at al [38] reported a single center retrospective study reported adults patients with pGBM treated with bevacizumabbased chemotherapy $(B B C)+\operatorname{TTF}(n=30)$ or TMZ, bevacizumab, irinotecan (TBI) + TTF. OS and PFS were significantly better for the TBI +TTF group, 18.9 and 10.7 months compared to 11.8 and 4.7 months in the BBC+TTF group. The authors conclude that the TBI regimen might play a role in treatment of adult patients with pGBM.

Kezari and Ram [39] report a post-hoc analysis of the EF-14 trial which was performed in newly diagnosed GBM patients [Stupp et al 2017]. Patients who failed trial EF-14, were treated with TTF+ chemotherapy at first recurrence $(n=144)$ or $(n=60)$ received chemotherapy alone. The median OS was significantly longer than in the experimental group: 1.8 versus 9.2 months. No grade 3 or 4 toxicities were observed. The authors concluded that TTF plus chemotherapy after first disease recurrence on TTF plus TMZ or TMZ alone prolonged OS in patients in the EF-14 trial without added toxicity. This study provides Class III evidence because it is a retrospective analysis of a phase III trial.

Ansstas et al [40] treated a small group of adult patients $(n=8)$ with TTF after they showed evidence of recurrence while treated with bevacizumab. Pulse bevacizumab was re-started at progression. Median OS from last dose of initial bevacizumab was 237 days ( 7.9 months), twice that of historical controls for bevacizumab failures. They conclude that the use of TTF therapy with pulse dose bevacizumab as an option in patients with refractory GBM.

Wong et al [41] in a single center retrospective study compare two groups of adult patients with pGBM. A small group $(n=3)$ were treated with TTF+bevacizumab+TCCC (6-thioguanine $[80 \mathrm{mg} / \mathrm{m} 2$ every 6 hour from days 1 to 3] lomustine [ $100 \mathrm{mg} / \mathrm{m} 2$ on day 4] capecitabine [ $825 \mathrm{mg} / \mathrm{m} 2$ every 12 hour from day 5] celecoxib $400 \mathrm{mg}$ every 12 hour from days 11 to 24 . The cycle is repeated every 42 days or 6 weeks. All medications are oral). The control group received TTF+bevacizumab $(n=35)$. A trend in prolonged OS was found patients treated with TTF+bevacizumab+TCCC. Though TTF is used in this study, it does not provide support for or against the use of TTF in terms of survival or toxicity.

Stupp et al [43] reported a phase III multi-center trial in patients with pGBM treated with TTF $(n=120)$ compared to chemotherapy ( $n=117)$, trial known as EF-11. Median OS was 6.6 versus 6.0 months, PFS rate at 6 months was $21.4 \%$ 
and $15.1 \%(p=0.13)$, respectively in TTF and chemotherapy patients, thus demonstrating no survival benefit for TTF. Although improvement in OS was not demonstrated, efficacy and activity with this chemotherapy-free treatment device appeared comparable to chemotherapy regimens commonly used for pGBM. Toxicity favored TTF. This paper provided Class II evidence.

\section{Q4- Synthesis}

Class II evidence does state that in adult patients with pGBM TTF provides similar survival rates to chemotherapy with decreased toxicity. However, the question here is asking if TTF provides increased survival over chemotherapy. The evidence available is inconclusive or conflicting and insufficient to clearly answer that query. The use of TTF with other chemotherapy could be considered at the discretion of the managing physician when treating adult patients with pGBM based on the class III evidence from four recent papers.

Question (Q5): In adult patients with pGBM does the use of oncolytic virotherapy result in increased survival compared to chemotherapy?

The field of oncolytic virotherapy encompasses any use of viruses with natural or engineered tumor- selective replication to intentionally infect and kill tumor cells. The defining concept of virotherapy is a conditional, tumorrestricted viral replication with subsequent lysis of tumor cells. This selective replication is based on inherent or engineered mechanisms that exploit tumor cell aberrations for viral propagation. While the concept of using live viruses to infect and destroy tumors dates back over a century ago, the ease of creating novel genetically engineered viruses using molecular biology has accelerated the field of oncolytic viral therapy in the last two decades. There were 8 papers that met our eligibility criteria to document their use for treatment of patients with pGBM (Table 5) [43-50]. These studies are all phase I trials providing Class III evidence.

Lang et al [44] reported a single center Phase 1 trial with 37 patients with pGBM treated with the oncolytic adenovirus DNX-2401 (Delta-24-RGD; tasadenoturev). The trial was divided in two phases: Phase I A Dose-escalation with 8 dose levels in 25 pts; Phase IB permanent catheter with intra-tumoral injection followed by resection 14 days later in 12 pts. Dose-limiting toxicities were not observed in the study. $20 \%$ of patients survived $>3$ years from treatment, and three patients had $\mathrm{a}=95 \%$ reduction in the enhancing tumor $(12 \%)$, with all three of these dramatic responses resulting in > 3 years of progression- free survival from the time of treatment. Direct virus-induced oncolysis was documented. Treatment with DNX-2401 resulted in dramatic responses with long-term survival in recurrent high- grade gliomas that are probably due to direct oncolytic effects of the virus followed by elicitation of an immune-mediated anti-glioma response.

Geletneky et al [45] conducted a multi-center phase I/Ila trial (ParvOryx01) using the oncolytic $\mathrm{H}-1$ parvovirus (H-1PV) in 18 patients with pGBM. The study had 2 arms. Arm 1: the first dose of H-1PV was injected intratumorally. Arm 2: five intravenous virus infusions on days 1-5. On day 10, all patients of both arms underwent tumor resection, and virus was re-injected around the resection cavity. H-1PV treatment showed no dose-dependent side effects or dose-limiting toxicity (DLT). PFS at 6 months was 27\%, and median PFS was 111 days. OS was 72\%, and median 0 s was 464 days. The Authors concluded that altogether H-1PV results provide an impetus for further H-1PV clinical development.

Cloughesy et al [46] reported on a phase 1, open-label, ascending dose, multicenter trial in 45 pts with recurrent HGG using Toca 511 (vocimagene amiretrorepvec) a oncolytic, retroviral replicating vector (RRV) that delivers a yeast cytosine deaminase, which converts subsequently administered courses of the prodrug Toca FC (extended-release 5fluorocytosine) into the antimetabolite 5-fluorouracil. OS was 13.6 months and was statistically improved relative to 
external control. The favorable assessment of TOCA 511 and Toca FC supports confirmation in a randomized phase 2/3 trial (NCT02414165), currently ongoing.

Kicielinski et al [47] conducted a multi-center phase I trial (REOLYSISN trial) in 12 patients with pGBM and 3 high-grade glioma patients using the oncolytic reovirus. This was a dose escalation study ranging from $1 \times 10(8)$ to $1 \times 10(10)$ tissue culture infectious dose 50, ten times the dose achieved in Forsyth et al [2008]. There was 1 grade 3 adverse event (seizure), no grade 4. MTD was not achieved. The intratumoral infusion of reovirus in patients with recurrent malignant glioma demonstrated the approach to be safe and well tolerated, warranting further studies.

Markert et al [48] conducted a single center phase I trial using the oncolytic herpes simplex virus (HSV) G207, a doubly mutated (deletion of both y134.5 loci, insertional inactivation of UL39) in six pGBM patietns. This was stereotactically inoculated with total two doses of totaling to $1.15 \times 109$ plaque-forming units. One patient experienced transient fever, delirium, and hemiparesis, which entirely resolved on high-dose dexamethasone. Radiographic and neuropathologic evidence suggestive of antitumor activity was reported. Evidence of viral replication was demonstrated.G207 appears safe for multiple dose delivery, including direct inoculation into the brain surrounding tumor resection cavity.

Forsyth et al [49] conducted a single center phase I trial in Canada on 12 patients with recurrent high grade glioma, 9 of which had pGBM, using the oncolytic reovirus. The Authors injected 107- 109 pfu of reovirus to 3 intratumoral sites in each patient. No significant toxicity was reported and the MTD was not reached. There was one patient with a more than 6-year survival. The Authors concluded that intratumoral administration of the genetically unmodified reovirus was well tolerated using these doses and schedule, in patients with recurrent high grade gliomas.

Freemen et al [50] conducted a single center phase I/II trial using the NDV-HUJ strand of the Newcastle Disease virus (NDV), an avian paramyxovirus with a negative stranded RNA genome, which is not associated with any serious human disease. This was delivered intravenously to 13 patients with pGBM. Toxicity was minimal with Grade I/II constitutional fever being seen in 5 patients. MTD was not achieved. TTP ranged from 2 to 37 weeks. OS ranged from 3 to 66 weeks. Anti-NDV hemagglutinin antibodies appeared within 5-29 days. NDV-HUJ was recovered from blood, saliva, and urine samples and one tumor biopsy. The Authors conclude that the study findings of good tolerability and encouraging responses warrant the continued evaluation of NDV-HUJ in GBM.

Chiocca et al [51] conducted a phase 1 trial with intratumoral injection of the oncolyticadenovirus ONYX-015, an adenovirus mutant that is thought to replicate more efficiently in cells with disruptions in the p53 tumor suppressor pathway (such as tumor cells). Twenty-four patients with recurrent high grade gliomas, including pGBM, received up to 1010 pfu at 10 different sites at the tumor resection border. No significant toxicity was noted. ONYX-015 application was not associated with a therapeutic effect. There were no serious adverse events (AEs). MTD was not achieved. The TTP after treatment with ONYX-015 was 46 days (range 13- 452). The median survival time was 6.2 months (range 1.3 -28.0). The Authors concluded that injection of ONYX-015 into glioma cavities is well tolerated at doses up to $1010 \mathrm{pfu}$.

\section{Q5-Synthesis}

Since the Martuza's group pioneering study in 1991 [52] over 20 viruses have been recognized as potential oncolytic therapeutic. Our literature review showed 8 clinical trials over 19 years using this therapy in patients with pGBM. The oncolytic viruses tested were adenovirus ONYX-015, adenovirus DNX-240, herpes simplex HSV G207, New Castle disease NCD- HUJ, parvovirus H-1PV, and parvovirus, reovirus. The latter in two phase I trials: one single and one multicenter. Although the safety profile of the above virus seems safe, the benefits have not been shown by studies reviewed. 
The oncolytic retroviral replicating vector (RRV) Toca 511 (vocimagene amiretrorepvec) had shown promising benefits on overall survival of pGBM, which warranted the phase II/III trial. This trial concluded after the time of this literature review reporting negative results [53].

\section{Relationship of Quality of Life to Chemotherapeutic Agent Choice}

The lack of Class I evidence in treating patients with pGBM and the abundance of Class III evidence raises the question that when evaluating therapeutic interventions quality of life should play a significant role. The writers initially created a question related to this and carried out literature search to address this issue as detailed in Methods, Search \#2. Only one paper met our preliminary search criteria assessing the impact of therapy on patients' health-related quality of life (HRQoL). A second paper addressed QoL as a secondary end-point (Table 6) [42,53]

Stockelmaier et al [54] in a prospective multi-center study in 110 cases assessed health-related quality of life (HRQoL) 1 year after diagnosis of recurrent HGG, including 84 with pGBM [ERASMUS trial]. They analyzed the European Organization for Research and Treatment of Cancer Quality of Life core questionnaire and European Organization for Research and Treatment of Cancer Quality of Life Questionnaire-Brain Neoplasm module questionnaires in an unselected cohort. The authors report that patients receiving second-line chemotherapy showed moderately better physical and role functioning as well as less motor dysfunction than patients receiving third-line chemotherapy. Results were available in 92/110 cases. When they compared HRQoL after second-line chemotherapies, patients receiving intensified temozolomide dosages demonstrated a moderately better outcome for cognitive functioning and less communication deficits $(P=0.055)$ than patients treated with bevacizumab. Regarding number of recurrent surgeries, they found stable HRQoL scores until second recurrent surgery, whereas after third recurrent surgery HRQoL decreased. The authors concluded that their results from an unselected cohort of recurrent HGGs show that the currently available treatment options have no negative impact on HRQoL. Thus, they implied treatment decisions regarding chemotherapy can be made individually, without fear of jeopardizing HRQoL for better survival. However, only $75 \%$ of the patients included in this study had progressive glioblastoma and the information from them could not be separated from those without this tumor type and therefore the paper is not eligible for inclusion I this guideline. Additionally, even if the publication met eligibility criteria, quality of life questionnaires could be sent out as late as a year after recurrence. This leads to two sources of substantial bias, firstly, it selects for those that survive longer after recurrence and have a better prognosis and because a year can have elapsed after the treatment progression, recall bias will clearly enter into the provision of information for the forms. Given the ineligibility and bias concerns, use of this paper for creation of a recommendation could not be justified.

As reviewed in the section above (pertinent to Q4) Stupp et al [43] reported a phase III multi-center trial in patient with pGBM treated with TTF $(n=120)$ compared to chemotherapy $(n=117)$, trial known as EF-11. Median OS was 6.6 versus 6.0 months, PFS rate at 6 months was $21.4 \%$ and $15.1 \%(p=0.13)$, respectively in TTF and chemotherapy patients. Improvement in OS was not demonstrated as efficacy and activity with this chemotherapy-free treatment device appeared comparable to chemotherapy regimens commonly used for pGBM. Adverse events were significantly more common in patients undergoing chemotherapy (16\% versus 6\%). Quality of life (QoL)data was available in 63 patients (27\%). In the domains of global health and social functioning no meaningful differences between chemotherapy and TTF were observed. However, cognitive and emotional functioning favored TTF. Physical functioning was slightly worse with TTF, while role functioning favored TTF. Appetite loss, diarrhea, constipation, nausea and vomiting were directly related to the chemotherapy administration. Increased pain and fatigue was reported in the chemotherapytreated patients and not in the TTF treatment group. That said, data pertinent to QoL comprises only $27 \%$ of the study population. Therefore there is no realistic means to conclude the study was adequately powered for quality of life 
conclusions as the minority of patients provided quality of life responses. Therefore there is insufficient evidence to make a recommendation on QoL related to TTF in comparison to chemotherapy.

The specific question of QoL was not addressed by the pervious guideline [1]. Because this is clearly an important topic across all disciplines within oncology it was initially addressed in this guidelines. Though a number of citations dealing with quality of life were at least tangentially related to progressive glioblastoma, no publications meeting inclusion criteria and performance criteria were identified. The two citations that met preliminary screening and entered in Table 6 are maintained in this document to serve as a resource in future versions of this guideline.

\section{Conclusions And Key Issues For Future Investigation}

Systemic chemotherapy is broadly used for patients with pGBM. Presently, no systemic drug is supported by Level II recommendation for treatment of patients with pGBM. Most chemotherapy drugs receive Level III recommendation for use in the treatment of patients with pGBM. There is also Level III recommendation that other cytotoxic therapies should not be used for pGBM, such as platinum compounds, topoisomerase inhibitors, perillyl acohol, ketogenic diet, and virotherapy.

Regarding in situ chemotherapy, prior to Stupp regimen [4], Class II evidence based on a single study, showed benefit of in situ BCNU wafers implantation. After the Stupp regiment has been implement across the board, there is insufficient evidence to make a suggestion about the use of in situ nitrosourea in patients with pGBM who underwent the Stupp regimen.

There is Class II evidence that TTF used for patients with pGBM results in similar overall survival than chemotherapy with decreased toxicity. That study was not powered to look at the financial implications of TTF. Its cost and lack of availability might pose a barrier to its use across the board. Additional efforts to overcome these barriers are necessary. Future directions to possibly decrease the financial burden, could involve its use in combination with other therapies resulting in a shorter course. As shown by pre-clinical studies, TTFs may alter the genetic signature of treated tumors and make them susceptible to particular chemotherapeutic agents [54]. This could potentially make GBM cells more susceptible to mitosis inhibitors or, as discussed above, expand the application of chemo-/targeted therapy. Finally, there is some work demonstrating that TTFs may activate local immune responses and could therefore have interplay with immunotherapy in the future [55]. Future prospective studies on quality of life in patients with pGBM should be the focus of our next decades as they are still very scarce and yet potentially very important to help the patient-physician treatment choice.

\section{Abbreviations}

OS: Overall survival

PFS: progression-free survival

PFS6: 6 month progression-free survival

PR: Partial Response

CR: complete response

SD: stable disease

GBM: glioblastoma multiforme

Page 16/46 
TMZ: temozolomide

NU: nitrosourea

ORR: objective response rate

TFI: treatment free interval

BBC: Bevacizumab-based chemotherapy

Bev: Bevacizumab

TCCC: 6-thioguanine, lomustine, capecitabine, celecoxib

TBI: TMZ, Bev, irinotecan

TTF: Tumor Treating Fields

\section{Declarations}

Disclosures: These guidelines were funded exclusively by the Congress of Neurological Surgeons (CNS) and the Joint Section on Tumors, which received no funding from outside commercial sources to support the development of this document.

\section{Data transparency}

All authors have ensured all data and materials as well as software applications or custom code supports their published claims and comply with field standards.

\section{Author statement}

All authors listed on this publication agree with the content included and give explicit consent to the submission of this publication. The authors obtained consent from the responsible authorities at the institute/organization where the work has been carried out, before the work was submitted.

All authors whose names appear on the submission:

1) made substantial contributions to the conception or design of the work; or the acquisition, analysis, or interpretation of data; or the creation of new software used in the work;

2) drafted the work or revised it critically for important intellectual content.

\section{Conflict of Interest (COI)}

All Guideline Task Force members were required to disclose all potential COls prior to beginning work on the guideline, using the COI disclosure form of the AANS/CNS Joint Guidelines Review Committee. The CNS Guidelines Committee and Guideline Task Force Chair reviewed the disclosures and either approved or disapproved the nomination and participation on the task force. The CNS Guidelines Committee and Guideline Task Force Chair may approve nominations of task force members with possible conflicts and restrict the writing, reviewing, and/or voting privileges of that person to topics that are unrelated to the possible COls. The authors have no personal, financial, or institutional interest in any of the drugs, materials, or devices described in this series of articles. 


\section{Disclosures}

These guidelines were funded exclusively by the Congress of Neurological Surgery and the Joint Section on Tumors of the Congress of Neurological Surgeons and the American Association of Neurological Surgeons, which received no funding from any outside commercial sources to support the development of this document.

\section{Disclaimer of Liability}

This clinical systematic review and evidence-based guideline was developed by a multidisciplinary physician volunteer task force and serves as an educational tool designed to provide an accurate review of the subject matter covered. These guidelines are disseminated with the understanding that the recommendations by the authors and consultants who have collaborated in their development are not meant to replace the individualized care and treatment advice from a patient's physician(s). If medical advice or assistance is required, the services of a competent physician should be sought. The proposals contained in these guidelines may not be suitable for use in all circumstances. The choice to implement any particular recommendation contained in these guidelines must be made by a managing physician in light of the situation in each particular patient and on the basis of existing resources.

\section{Acknowledgements}

The guidelines task force would like to acknowledge the Congress of Neurological Surgeons Guidelines Committee for their contributions throughout the development of the guideline, and the American Association of Neurological Surgeons/Congress of Neurological Surgeons Joint Guidelines Review Committee for their review, comments, and suggestions throughout peer review, as well as the contributions of Trish Rehring, MPH, CHES, Senior Manager of Clinical Practice Guidelines for the CNS, and Mary Bodach, MLIS, from the Congress of Neurological Surgeons Guidelines Office for organizational assistance and reference librarian services, respectively as well as Jeremy Kupsco, PhD, Informationist, Emory University, for their valuable input as Medical Research Librarians. Throughout the review process, the reviewers and authors were blinded from one another. At this time the guidelines task force would like to acknowledge the following individual peer reviewers for their contributions: John O'Toole, MD, Brian Howard, MD, Jamie Van Gompel, MD, Howard Silberstein, MD, Navid Redjal, MD and Shawn Hervey-Jumper, MD.

\section{References}

1. Olson JJ, Nayak L, Ormond DR, Wen PY,Kalkanis, SN (2014) The role of cytotoxic chemotherapy in the management of progressive glioblastoma. J Neurooncol 118:501-555.

2. Yung WK, Albright RE, Olson JJ et al (2000) A phase II study of temozolomide vs procarbazine in patients with glioblastoma multiforme at first relapse. Brit j cancer 83(5):588-593.

3. Brem H, Piantadosi S, Burger PC et al (1995) Placebo-controlled trial of safety and efficacy .of intra-operative controlled biodegradable polymers of chemotherapy for recurrent gliomas. The polymer-brain tumor treatment group. Lancet 345(8956):1008-1012.

4. Stupp R, Mason WP, van den Bent MJ et al (2005) Radiotherapy plus concomitant and adjuvant temozolomide for glioblastoma. New Engl J Med 352(10):987-996.

5. Stupp R, Hegi ME, Mason WP, et al (2009) Effects of radiotherapy with concomitant and adjuvant temozolomide versus radiotherapy alone on survival in a randomized phase III study: 5-year analysis of the EORTC-NCIC trial. Lancet Oncol 10(5):459-466.

6. Wong ET, Timmons J, Callahan A, O'Loughlin L, Giarusso B, Alsop DC (2016) Phase I study of low-dose metronomic temozolomide for recurrent malignant gliomas. BMC cancer 16(1):914. 
7. van Vugt VA, Piccioni DE, Brown BD, et al (2014) Retrospective analysis of safety and feasibility of a 3 days on/11 days off temozolomide dosing regimen in recurrent adult malignant gliomas. CNS oncology 3(4):257-265

8. Han SJ, Rolston JD, Molinaro AM, et al (2014) Phase II trial of 7 days on/7 days off temozolmide for recurrent high-grade glioma. Neuro-oncology 16(9):1255-1262.

9. 9. Omuro A, Chan TA, Abrey LE,et al (2013) Phase II trial of continuous low-dose temozolomide for patients with recurrent malignant glioma. Neuro-oncology 15(2):242-250.

10. Archavlis E, Tselis N, Birn G, Ulrich P, Baltas D, Zamboglou N (2013) Survival analysis of HDR brachytherapy versus reoperation versus temozolomide alone: a retrospective cohort analysis of recurrent glioblastoma multiforme. BMJ Open 2013;3:e002262. doi:10.1136/bmjopen-2012-002262

11. 11. Norden AD, Lesser GJ, Drappatz J, et al (2013) Phase 2 study of dose-intense temozolomide in recurrent glioblastoma. Neuro-oncology 15(7):930-935.

12. 12. Roussakow SV (2017) Clinical and economic evaluation of modulated electrohyperthermia concurrent to dosedense temozolomide $21 / 28$ days regimen in the treatment of recurrent glioblastoma: a retrospective analysis of a two-centre German cohort trial with systematic comparison and effect-to-treatment analysis. BMJ open 7(11):e017387

13. Aoki T, Arakawa Y, Ueba T, et al (2017) Phase I/II Study of Temozolomide Plus Nimustine Chemotherapy for Recurrent Malignant Gliomas: Kyoto Neuro-oncology Group. Neurologia medico-chirurgica 57(1):17-27.

14. Wang L, Liang L, Yang T, et al (2017) A pilot clinical study of apatinib plus irinotecan in patients with recurrent high-grade glioma: Clinical Trial/Experimental Study. Medicine 96(49):e9053.

15. Reynes G, Martinez-Sales V, Vila V, et al (2016) Phase II trial of irinotecan and metronomic temozolomide in patients with recurrent glioblastoma. Anti-cancer drugs 27(2):133-137.

16. Di Cristofori A, Zarino B, Fanizzi C, et al (2017) Analysis of factors influencing the access to concomitant chemoradiotherapy in elderly patients with high grade gliomas: role of MMSE, age and tumor volume. Journal of neurooncology 134(2):377-385.

17. Franceschi E, Stupp R, van den Bent MJ, et al (2012) EORTC 26083 phase I/II trial of dasatinib in combination with CCNU in patients with recurrent glioblastoma. Neuro-oncology 14(12):1503-1510.

18. Marinellli A, Cerbone L, Cordua N, Buonerba C, Peluso G, Di Lorenzo G and De Placido S (2018) High-dose fotemustine in temozolomide-pretreated glioblastoma multiforme patients: A phase I/II trial. Medicine 97(27):e11254.

19. Klein J, Juratli TA, Radev Y, et al (2017) Safety and Effectiveness of Bis-Chloroethylnitrosourea Wafer Chemotherapy in Elderly Patients with Recurrent Glioblastoma. Oncology 93(1):43-50.

20. Perez-Segura P, Manneh R, Ceballos I, et al (2016) GEINOFOTE: efficacy and safety of fotemustine in patients with high-grade recurrent gliomas and poor performance status. Clinical \& translational oncology : official publication of the Federation of Spanish Oncology Societies and of the National Cancer Institute of Mexico 18(8):805-812.

21. Lombardi G, Bellu L, Pambuku A, Della Puppa A, Fiduccia P, Farina M, D'Avella D and Zagonel V (2016) Clinical outcome of an alternative fotemustine schedule in elderly patients with recurrent glioblastoma: a monoinstitutional retrospective study. J Neurooncol 128:481-6.

22. Carvalho BF, Fernandes AC, Almeida DS, et al (2015) Second-Line Chemotherapy in Recurrent Glioblastoma: A 2Cohort Study. Oncology research and treatment 38(7-8):348-354.

23. Mack F, Schafer N, Kebir S, Stuplich M, Schaub C, Niessen M, Scheffler B, Herrlinger U and Glas M (2014) Carmustine (BCNU) plus Teniposide (VM26) in recurrent malignant glioma. Oncology 86: 369-72. 
24. Santoni M, Scoccianti S, Lolli I, Fabrini MG, Silvano G, Detti B, Perrone F, Savio G, lacovelli R, Burattini L, Berardi R and Cascinu S (2013) Efficacy and safety of second-line fotemustine in elderly patients with recurrent glioblastoma. J Neurooncol 1113:397-401.

25. De Felice F, Bulzonetti N, Musio D, D'Elia A, Salvati M, Tombolini V (2013) Low-dose fotemustine as second-line chemotherapy for recurrent glioblastoma multiforme. Anticancer research 33(9):4013-4016.

26. Weller M, van den Bent M, Tonn JC, Stupp R, Preusser M, Cohen-Jonathan-Moyal E, et al (2017) European Association for Neuro-Oncology (EANO) guideline on the diagnosis and treatment of adult astrocytic and oligodendroglial gliomas. Lancet Oncol 18:e315-29. https://doi.org/10.1016/S1470-2045(17)30194-8.

27. Alexander BM, Ba S, Berger MS, Berry DA, Cavenee WK, Chang SM, et al (2018) Adaptiveglobal innovative learning environment for glioblastoma: GBM AGILE. Clin Cancer Res 24:737-43. https://doi.org/10.1158/1078-0432.CCR17-0764.

28. Fiorentini G1, Sarti D1, Milandri C2, Dentico P2, Mambrini A3, Fiorentini C4, Mattioli G1, Casadei V1, Guadagni S5. Modulated Electrohyperthermia in Integrative Cancer Treatment for Relapsed Malignant Glioblastoma and Astrocytoma: Retrospective Multicenter Controlled Study. Integr Cancer Ther. 2019 Jan-Dec; Epub 2018 Dec 22.PMID: 30580645

29. Silvani A, De Simone I, Fregoni V, Biagioli E, Marchioni E, Caroli M, Salmaggi A, Pace A, Torri V, Gaviani P, Quaquarini E, Simonetti G, Rulli E and D'Incalci M (2019) Multicenter, single arm, phase II trial on the efficacy of ortataxel in recurrent glioblastoma. J Neurooncol 142:455-462.

30. Jia PF, Gu WT, Zhang WF, Li F (2015) Treatment of recurrent malignant gliomas with 13-cis-retinoic acid naphthalene triazole. Neurological sciences : official journal of the Italian Neurological Society and of the Italian Society of Clinical Neurophysiology 6(5):717-721.

31. Roci E, Cakani B, Brace G, Bushati T, Rroji A, Petrela M and Kaloshi G (2014) A randomized phase I/II study of ABT888 in combination with temozolomide in recurrent temozolomide resistant glioblastoma: an NRG oncology RTOG group study. J Neurooncol 126:309-16

32. Rieger J, Bahr O, Maurer GD, et al (2014) ERGO: a pilot study of ketogenic diet in recurrent glioblastoma. International journal of oncology 44(6):1843-1852.

33. Tonder M, Weller M, Eisele G and Roth P.(2014) Carboplatin and Etoposide in Heavily Pretreated Patients with Progressive High-Grade Glioma. Chemotherapy 60:375-8.

34. Da Fonseca CO, Teixeira RM, Silva JCT, Fisher JDG, Meirelles OC, Landeiro JA, Quirico-Santos T(2013) Long term outcome in patietns with recurrent malignat glioma treated with Perillyl Alcohol inhalation. Anticancer Research 33:5625-5631.

35. Hu J, Wen PY, Abrey LE, Fadul CE, Drappatz J, Salem N, Supko JG and Hochberg F (2013) A phase II trial of oral gimatecan for recurrent glioblastoma. J Neurooncol 111:347-353.

36. Giladi M, Schneiderman RS, Voloshin T, et al (2015) Mitotic spindle disruption by alternating electric fields leads to improper chromosome segregation and mitotic catastrophe in cancer cells. Sci Rep 5:18046.

37. Kirson ED, Dbalý V, Tovarys F, et al (2017) Alternating electric fields arrest cell proliferation in animal tumor models and human brain tumors. Proc Natl Acad Sci U S A. 104(24):10152-10157.

38. Lu G, Rao M, Zhu P, et al (2019) Triple-drug Therapy With Bevacizumab, Irinotecan, and Temozolomide Plus Tumor Treating Fields for Recurrent Glioblastoma: A Retrospective Study. Frontiers in neurology 10:42.

39. Kesari S, Ram Z (2017) Tumor-treating fields plus chemotherapy versus chemotherapy alone for glioblastoma at first recurrence: a post hoc analysis of the EF-14 trial. CNS oncology 6(3):185-193. 
40. Ansstas G, Tran DD (2016) Treatment with tumor-treating fields therapy and pulse dose bevacizumab in patients with bevacizumab-refractory recurrent glioblastoma: a case series. Case Rep Neurol 8:1-9.

41. Wong ET, Lok E, Swanson KD (2015) Clinical benefit in recurrent glioblastoma from adjuvant NovoTTF-100A and TCCC after temozolomide and bevacizumab failure: a preliminary observation. Cancer medicine 4(3):383-391.

42. Rulseh AM, Keller J, Klener j et al J (2012) Long-term survival of patients suffering from glioblastoma multiforme treated with tumor-treating fields. World J Surg Oncol.10:220

43. Stupp R, Wong ET, Kanner AA, et al (2012) NovoTTF-100A versus physician's choice chemotherapy in recurrent glioblastoma: a randomised phase III trial of a novel treatment modality. European journal of cancer (Oxford, England : 1990) 48(14):2192-2202.

44. Lang FF, Conrad C, Gomez-Manzano C, et al (2018) Phase I Study of DNX-2401 (Delta-24-RGD) Oncolytic Adenovirus: Replication and Immunotherapeutic Effects in Recurrent Malignant Glioma. Journal of clinical oncology : official journal of the American Society of Clinical Oncology 36(14):1419-1427.

45. Geletneky K, Hajda J, Angelova AL, et al (2017) Oncolytic H-1 Parvovirus Shows Safety and Signs of Immunogenic Activity in a First Phase I/Ila Glioblastoma Trial. Molecular therapy : the journal of the American Society of Gene Therapy 25(12):2620-2634.

46. Cloughesy TF, Landolfi J, Hogan DJ, Bloomfield S, Carter B, Chen CC, Elder JB, Kalkanis SN, Kesari S, Lai A, Lee IY, Liau LM, Mikkelsen T, Nghiemphu PL, Piccioni D, Walbert T, Chu A, Das A, Diago OR, Gammon D, Gruber HE, Hanna M, Jolly DJ, Kasahara N, McCarthy D, Mitchell L, Ostertag D, Robbins JM, Rodriguez-Aguirre M, Vogelbaum MA (2016) Phase 1 trial of vocimagene amiretrorepvec and 5-fluorocytosine for recurrent high-grade glioma. Sci Transl Med 8(341):341ra75.

47. Kicielinski KP, Chiocca EA, Yu JS, Gill GM, Coffey M, Markert JM (2014) Phase 1 clinical trial of intratumoral reovirus infusion for the treatment of recurrent malignant gliomas in adults. Mol Ther 22(5):1056-62. Epub 2014 Feb 20.

48. Markert JM, Liechty PG, Wang W, et al (2009) Phase Ib trial of mutant herpes simplex virus G207 inoculated preand post-tumor resection for recurrent GBM. Mol Ther.17:199-207.

49. Forsyth P, Roldan G, George D, et al (2008) A phase I trial of intratumoral administration of reovirus in patients with histologically confirmed recurrent malignant gliomas. Mol Ther 16:627-632.

50. Freeman Al, Zakay-Rones Z, Gomori JM, Linetsky E, Rasooly L, Greenbaum E, Rozenman-Yair S, Panet, A, Libson E, Irving CS, Galun E, Siegal T (2006) Phase I/II trial of intravenous NDV-HUJ oncolytic virus in recurrent glioblastoma multiforme. Mol Ther 13(1):221-8.

51. Chiocca EA, Abbed KM, Tatter S, Louis DN, Hochberg FH, Barker F, Kracher J, Grossman SA, Fisher JD, Carson K, Rosenblum M, Mikkelsen T, Olson J, Markert J, Rosenfeld S, Nabors LB, Brem S, Phuphanich S, Freeman S, Kaplan R, Zwiebel J. (2004) A phase I open-label, dose-escalation, multi-institutional trial of injection with an E1BAttenuated adenovirus, ONYX-015, into the peritumoral region of recurrent malignant gliomas, in the adjuvant setting. Mol Ther 10(5):958-66.

52. Martuza RL, Malick A, Markert JM, Ruffner KL, Coen DM (1991)Experimental therapy of human glioma by means of a genetically engineered virus mutant. Science 252:854-856.

53. Cloughesy T, Petrecca T, Walbert T, et al (2019) LTBK-08. Toca 511 \& Toca FC versus standard of care in patients with recurrent high grade gliomaNeuro-Oncology, Volume 21, Issue Supplement_6, November 2019, Page vi284, https://doi.org/10.1093/neuonc/noz219.1199

54. Stockelmaier L, Renovanz M, Konig J, et al (2017) Therapy for Recurrent High-Grade Gliomas: Results of a Prospective Multicenter Study on Health-Related Quality of Life. World neurosurgery 102:383-399.

Page 21/46 
55. Chang E, Pohling C, Beygui N, Patel CB, Rosenberg J, Ha DH, Gambhir SS (2017) Synergistic inhibition of glioma cell proliferation by Withaferin A and tumor treating fields. J Neurooncol.134, pages259-268.

56. Holtzman T, IMST-26 (2016) Tumor treating fields exposure of tumor cells induce activation phenotype in immune cells. Neuro Oncology 18: S6,Page vi92.

\section{Tables}

Table 1A. Cytotoxic chemotherapy for pGBM patients: temozolomide alone 


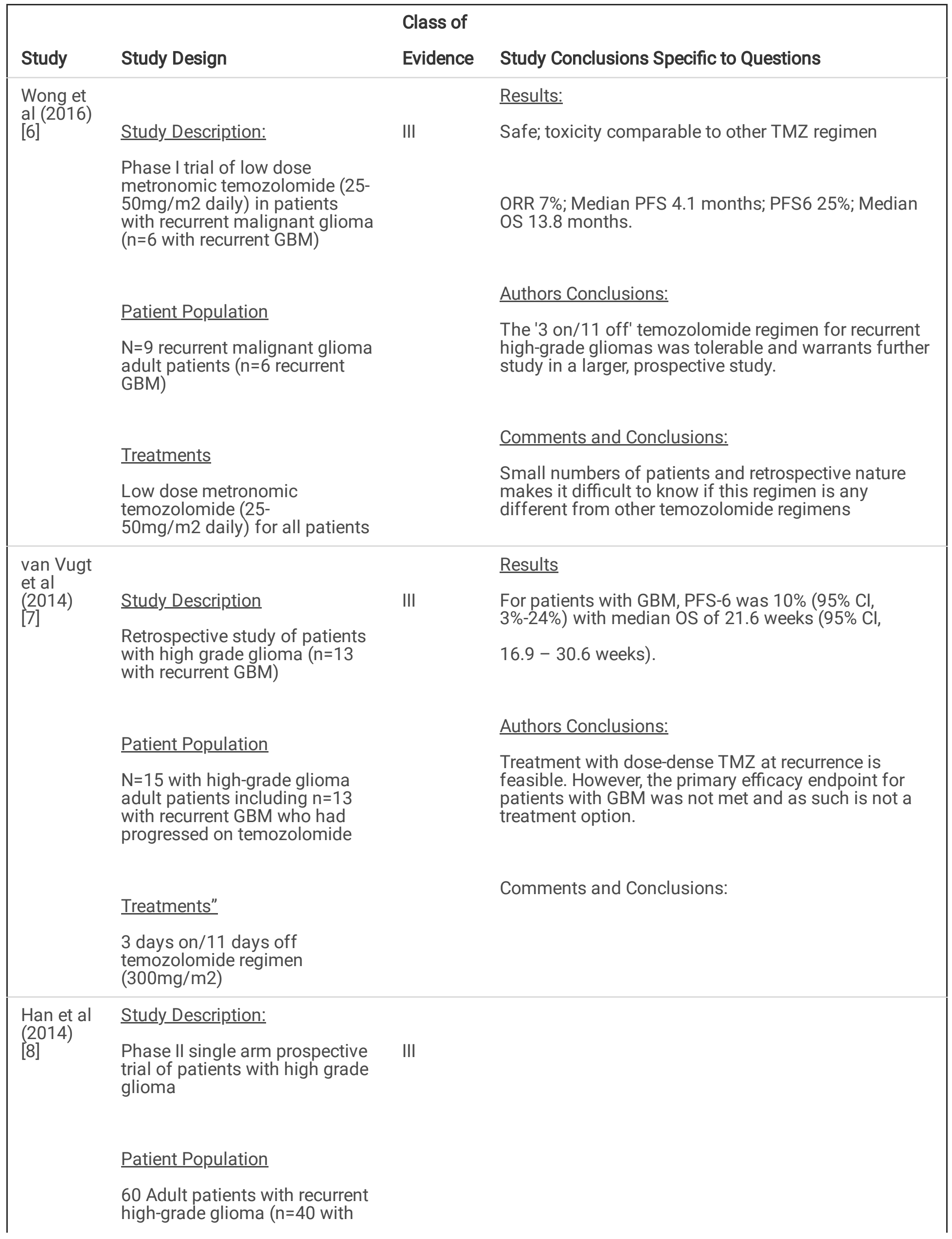


recurrent GBM)

\section{Treatments:}

All patients were treated with temozolomide (TMZ) 150

$\mathrm{mg} / \mathrm{m} 2$ for 7 consecutive days.

Given

on Day $1-7$ and $15-21$ of a

28 days cycle for

12 cycles.
This was a single arm phase II trial with only 40 patients. It showed that treatment with dense dose TMZ in recurrent GBM is feasible, however did not the primary pre-defined end point for GBM patients and as such not recommended as treatment options for these patients.
Omuro et

al.

(2013)

[9]

\section{$\underline{\text { Results: }}$}

III Clinical benefit (CR+PR+SD) in $36 \%$ of patients
PFS6 was $19 \%$

\section{Median OS was 7 months}

Patients with previous bevacizumab exposure survived significantly less than bevacizumab- naive patients (median overall survival: 4.3 months vs 13 months; hazard ratio $=3.2 ; \mathrm{P}=$

$.001)$, but those patients had lower KPS $(P=.04)$ and higher number of recurrences $(P<.0001)$.

\section{Authors Conclusions:}

In spite of a heavily pretreated population, including nearly half of patients having failed bevacizumab, the primary endpoint was met, suggesting that this regimen deserves further investigation.

\section{Comments and Conclusions:}

Very limited activity, if any despite authors' suggestion of benefit

\section{Results:}

The HDR-BRT group did significantly better than both the reoperation $(p<0.05)$ and the ddTMZ groups $(p<0.05)$.

Moderate to severe complications in the HDR-BRT,

\section{Authors Conclusions:}

111 pGBM patients

The survival benefit of ddTMZ is lower than HDR-BRT 
Treatments:

ddTMZ or re-resection or interstitial high dose rate brachytherapy (HDR-BRT)

Norden

et al.

(2013)

[11]
Results:

III

$13 \%$ PR and PFS6 of $11 \%$.

PFS6 $35.4 \%$

Median OS was 11.7 months

MGMT methylated patients had longer OS but not PFS

\section{Authors Conclusions:}

Dose-intense temozolomide on this schedule is safe in recurrent GBM. However, efficacy is marginal and predictive biomarkers are needed.

\section{Patient Population:}

58 patients with recurrent GBM

\section{Treatments:}

Dense TMZ dose: 75-

$100 \mathrm{mg} / \mathrm{m} 2 /$ day) for 21 days of every 28 day cycle

\section{Comments and Conclusions:}

Very limited activity and response not greatly influenced by MGMT status.

Abbreviations: OS= Overall survival; PFS= progression-free survival; PFS6: 6 month progression-free survival;

$\mathrm{PR}=$ Partial Response; $\mathrm{CR}=$ complete response; $\mathrm{SD}=$ stable disease; $\mathrm{GBM}=$ glioblastoma multiforme; $\mathrm{TMZ}=$ temozolomide

Table 1B. Cytotoxic chemotherapy for pGBM patients: Temozolomide plus other chemotherapy. 


\begin{tabular}{|c|c|c|c|}
\hline Study & Study Design & $\begin{array}{l}\text { Class of } \\
\text { Evidence }\end{array}$ & Study Conclusions Specific to Questions \\
\hline \multirow{11}{*}{$\begin{array}{l}\text { Roussakow } \\
\text { et al (2017) } \\
\text { [12] }\end{array}$} & & & Results: \\
\hline & Study Description & III & ORR 20\% (7\% CR; 14\% PR) \\
\hline & \multirow{2}{*}{$\begin{array}{l}\text { Retrospective review of adult } \\
\text { patients with recurrent GBM }\end{array}$} & & $33 \% \mathrm{SD}$ \\
\hline & & & Median OS 7.7 months \\
\hline & Patient Population & & Authors Conclusion: \\
\hline & $\begin{array}{l}\mathrm{N}=54 \text { adult patients with } \\
\text { recurrent GBM }\end{array}$ & & $\begin{array}{l}\text { Modulated electrohyperthermia significantly } \\
\text { improves survival of patients receiving the dose } \\
\text { dense temozolomide using } 21 / 28 \text { days regimen. }\end{array}$ \\
\hline & $\underline{\text { Treatments }}$ & & \multirow{2}{*}{$\begin{array}{l}\text { Economic evaluation suggests that therapy is cost- } \\
\text { effective. }\end{array}$} \\
\hline & \multirow{2}{*}{$\begin{array}{l}\text { All patients were treated with } \\
\text { dose-dense }(21 / 28 \text { day } \\
\text { regimen) with modulated } \\
\text { electrohypothermia and } \\
\text { compared to data from cohorts } \\
\text { of patients treated on trials with }\end{array}$} & & \\
\hline & & & \multirow{2}{*}{$\begin{array}{l}\text { Comments and Conclusions: } \\
\text { Retrospective and somewhat unconventional } \\
\text { review. Despite claims of efficacy results of } \\
\text { treatment group not significantly different from } \\
\text { comparator group. Results will require validation in } \\
\text { prospective }\end{array}$} \\
\hline & dose-dense temozolomide only & & \\
\hline & & & randomized studies. \\
\hline \multirow{10}{*}{$\begin{array}{l}\text { Aoki et al } \\
\text { (2017) [13] }\end{array}$} & & & Results: \\
\hline & Study Description & III & For patients with GBM: \\
\hline & $\begin{array}{l}\text { Phase I study with TMB and } \\
\text { ACNU for adult patients with } \\
\text { recurrent high-grade glioma } \\
\text { Phase II in patients with } \\
\text { recurrent high-grade glioma } \\
\text { treated with TMZ and ACNU }\end{array}$ & & $\begin{array}{l}\text { Median PFS was } 10 \text { weeks. Median OS was } 10.3 \\
\text { months }(3-22 \text { months). } 1 \text {-year survival was } 44 \% \text {. } \\
\text { PFS at } 6 \text { months as } 21 \% \text {. Unable to determine } \\
\text { specific toxicities for GBM patients. But for all } \\
\text { patients: } 35 \% \text { experienced grade } 3-4 \text { toxicity, mainly } \\
\text { hematologic. }\end{array}$ \\
\hline & Patient Population $\mathrm{N}=49$ & & Authors Conclusion: \\
\hline & Recurrent GBM (73\%) & & \multirow{2}{*}{$\begin{array}{l}\text { Use of TMZ and ACNU at progression shows equal } \\
\text { or non-inferior efficacy in PFS and moderate } \\
\text { myelotoxicity and shows promising results for OS. } \\
\text { This regimen could be an option for GBMs. }\end{array}$} \\
\hline & & & \\
\hline & $\begin{array}{l}\text { Anaplastic oligodendroglioma } \\
(4 \%) \text {. }\end{array}$ & & \\
\hline & & & Comments and Conclusions: \\
\hline & $\underline{\text { Treatments }}$ & & $\begin{array}{l}\text { There is no comparison arm, as such classified as } \\
\text { class III evidence. Authors conclusions refer to }\end{array}$ \\
\hline & $\begin{array}{l}\text { Phase I: TMZ }(150 \mathrm{mg} / \mathrm{m} 2 / \text { day }) \\
\text { days } 1-5+\operatorname{ACNU}(30,35,40,45\end{array}$ & & $\begin{array}{l}\text { recurrent gliomas in general and not for GBM } \\
\text { patients in their study. }\end{array}$ \\
\hline
\end{tabular}


$\mathrm{mg} / \mathrm{m} 2 /$ day) day 15 in $15 \mathrm{pts}$.

ACNU MTD $=40 \mathrm{mg} / \mathrm{m} 2$

Phase II: in 40 pts treated with TMZ + ACNU MTD

Wang et al (2017) [14]

Study Description

Phase II study of continuous

$\mathrm{TMZ}$ and cisplatin in patients with recurrent GBM

\section{Patient Population}

$\mathrm{N}=27$ patients with recurrent GBM

\section{$\underline{\text { Treatments }}$}

All patients received continuous TMZ (50mg/m2 daily) + cisplatin $(40,30$, and 30

mg were given on days 1,2 , and 3)
Results:

III

Moderate toxicity Median TTP 23 weeks PFS6 37\%

PFS12 11.1\%

ORR $22.2 \%$

Median OS 50 weeks

\section{Authors Conclusion:}

Cisplatin with continuous dose-intense regimen of temozolomide had an acceptable level of toxicity and showed activity in patients with recurrent GBM.

\section{Comments and Conclusions:}

This regimen shows more activity than most other regimens for recurrent glioblastomas. However, it is difficult to know if any of the patients had pseudoprogression. Results will need to be replicated.

Results:

No responses. Stable disease in $37.5 \%$. PFS-6 20.8\%; Median PFS 11.6 weeks

dose of temozolomide (50mg/m2 daily) with irinotecan $(100 \mathrm{mg} / \mathrm{m} 2)$ in adult patients with recurrent GBM at first relapse

III al (2016)

[15]

Patient Population

Adult patients with recurrent GBM at first relapse $(n=27)$

Treatments

All patients received metronomic temozolomide

(50mg/m2 daily) with irinotecan $(100 \mathrm{mg} / \mathrm{m} 2$ on days 8 and 22 of 28 days cycles)

\section{Grade 3/4 adverse events included}

lymphopenia (15\%), fatigue, diarrhea and febrile neutropenia (3.7\% each), lymphopenia, neutropenia, and nausea/vomiting_(11.1\% each). One patient died from pulmonary embolism

\section{Authors Conclusions:}

Regimen is feasible but failed to improve the results obtained with other second-line therapies in recurrent glioblastoma.

\section{Comments and Conclusions:}

No benefit with addition of irinotecan to metronomic temozolomide
Di

Cristofori et al (2013)
Study Description

Results:

III 
Prospective single-arm single institution study in adult patients with recurrent GBM receiving dose-dense $T M Z$ (dd$\mathrm{TMZ})$

\section{Patient Population}

$\mathrm{N}=32$ adult patients with recurrent GBM

Treatment

All patients received dd-TMZ (75- $150 \mathrm{mg} / \mathrm{m} 2)$ _plus daily. tamoxifen $(80 \mathrm{mg} / \mathrm{m} 2$
OS was 17.5 months and Time to Tumor Progression after recurrence 7 months. There was no toxicity.

\section{Authors Conclusion:}

Combinatorial administration of tamoxifen and ddTMZ appeared to be well-tolerated, and potentially effective.
Franceschi

et al (2012)

[17]

\section{Study Description}

Retrospective chart review of 106 adult patients with recurrent GBM.

\section{Patient Population}

$\mathrm{N}=106$ adult patients with recurrent GBM

\section{$\underline{\text { Treatments }}$}

$\mathrm{N}=70$ received TMZ (150 - 200 $\mathrm{mg} / \mathrm{m} 2$ for 5 days each 28 days cycle) and

$\mathrm{N}=36$ received Nitrosourea chemotherapy (Fotemustine and lomustine standard

schedule) after a treatment free interval of at least 8 weeks from standard therapy
III Results:

Median PFS was 6.6 months. PFS was 7.2 (95\% Cl: 5.5-8.8) and 5.1 months (95\% Cl: 3.6 - 6.6) in TMZ

and Nitrosourea (NU) group respectively. When considering patients with Treatment Free Interval (TFI) of ? 5 months, PFS was 8.1 months $(95 \% \mathrm{Cl}$ : 5.0-11.3) and 5.8 months (95\% Cl: 3.6-8.1) for patients with $\mathrm{TFI}<5$ months treated with $\mathrm{TMZ}$ or nitrosourea $(p=0.020)$.

Median OS was 14.2 months and was significantly longer for patients on TMZ than those on nitrosourea (15.2 months vs 11.5 months, respectively; $p=0.020)$. In patients treated with $T M Z$ and TFI ? 5 months OS was 17.7 and 11.6 months respectively for patients treated with $\mathrm{TMZ}$ or Nitrosoureas.

Patients with TFI ? 5 months benefit from TMZ rechallenge at the time of recurrence.

\section{Authors Conclusions:}

TMZ rechallenge is a treatment option to be considered for patients with TFI > 5 months irrespective of MGMT status since it may prolong PFS and OS compared to NU

\section{Comments and Conclusions:}

Retrospective study as such classified as class III evidence.

Abbreviations: OS= Overall survival; PFS= progression-free survival; PFS6: 6 month progression-free survival; 
$\mathrm{PR}=$ Partial Response; $\mathrm{CR}=$ complete response; $\mathrm{SD}=$ stable disease; $\mathrm{GBM}=$ glioblastoma multiforme; $\mathrm{ORR}=$ objective response rate; $\mathrm{TMZ}=$ temozolomide; $\mathrm{dd}-\mathrm{TMZ}=$ dose dense $\mathrm{TMZ} ; \mathrm{TFI}=$ Treatment Free Interval

Table 2. Cytotoxic chemotherapy for pGBM patients: Systemic and in situ nitrosoureas. 


\section{Study Study Design Evidence Study Conclusions Specific to Questions}

\section{Marinelli Study Description}

et al

(2018)

[18]

\section{Patient Population}

$\mathrm{N}=37$ adult patients with recurrent GBM

\section{Treatments}

All patients were treated with Intravenous administration of fotemustine:

$\mathrm{N}=31$ received $120 \mathrm{mg} / \mathrm{m} 2 \mathrm{~N}=6$ received $140 \mathrm{mg} / \mathrm{m} 2$

Treatment was administered over 1 hour every 2 weeks for up to 1 year until disease progression, unacceptable toxicity or patient's withdrawal from the study.

Klein et al (2017)

[19]

\section{Study Description}

Retrospective study of adult patients with recurrent GBM

\section{Patient Population}

$\mathrm{N}=79$ patients with recurrent GBM and methylated MGMT promoter.

\section{Treatment}

$\mathrm{N}=24$ older than 65 years treated with BCNU wafers at time of recurrence.

$\mathrm{N}=16$ older than 65 years not treated with BCNU wafers at time of recurrence, only. supportive care

\section{Results:}

PFS after progression was 9.2 months in elderly $\mathrm{BCNU}$ group and 7.4 months in elderly non-BCNU group.

PFS was 6.7 months in younger group.

OS was respectively 17.2 months and 15.9 months. OS was 19 months in the younger group.

There was higher incidence of seizures and pneumonia in older BCNU group.

There was no significant statistical difference in PFS after recurrence in all patients between all 3 groups. 
Perez-

Segura et

al (2016)

[20]

Study Description

III

Retrospective study of patient with high-grade glioma treated with fotemustine

\section{Patient Population}

$\mathrm{N}=84$ with recurrent $\mathrm{GBM}$ and $\mathrm{N}=30$ with recurrent $\mathrm{AA}$

\section{Treatments}

All patients were treated with Fotemustine given with different schedules at first or second recurrence, standard or Addeo schedule.
Results:

Grade $3-4$ toxicity occurred in $28 \%$ of pts. There was no difference in OS or PFS in the different cohorts

\section{Authors conclusion:}

Use of fotemustine in patients with recurrent GBM is safe and has comparable activity with other available options.

\section{Comments and Conclusions:}

Classified as class III evidence due to the retrospective nature of the study.
Lombardi

et al

(2016)

[21]

\section{Study Description}

Retrospective study of adult patients with recurrent GBM

\section{Patient Population}

$\mathrm{N}=44$ patients older than 65 years of age with recurrent GBM.

\section{Treatment}

All patients received alternative fotemustine monotherapy at the time of recurrence $(80 \mathrm{mg} / \mathrm{m} 2)$

every 2 weeks for 5 consecutive administrations then every 4 weeks as maintenance.

\section{Results:}

PFS and OS after recurrence was respectively

4.1 months $(95 \% \mathrm{Cl} 3.1-5.2)$ and 7 months $(95 \%, \mathrm{Cl}$ 5.2-8.4). Patients with MGMT promoter methylation had longer PFS and OS from the beginning of fotemustine (4.5 vs 2.9 months; $p=0.001$ and 9.2 vs 4.5 months; $p=0.04$ respectively).

\section{Authors conclusion:}

Alternative fotemustine monotherapy at the time of recurrence may benefit elderly patients with good performance status. This schedule might result in a lower incidence of grade $3-4$ thrombocytopenia. Elderly patients with methylated MGMT who relapse after TMZ may be the best candidates.

\section{Comments and Conclusions:}

Classified as class III evidence because of retrospective nature of the study.

\section{Carvalho Study_Description}

et al

(2015)

[22]
Retrospective study of patients with progressive GBM treated with PCV or

bevacizumab/irinotecan

Patient Population
III

$\mathrm{N}=60$ Adult patients with recurrent GBM
Results:

The median PFS was 5 months $(95 \%$ Cl $3.8-$

6.2 months) and 3 months ( $95 \% \mathrm{Cl} 1.0-5.0$ months) in the $\mathrm{BI}$ and PCV group,

respectively. 


\section{Treatment}

$\mathrm{N}=19$ treated with $\mathrm{PCV}$ (Procarbazine $100 \mathrm{mg} / \mathrm{kg}$ per

OS 10 days, days $2-11$,

lomustine $100 \mathrm{mg} / \mathrm{m} 2$ P.O.

at day 1 and vincristine $2 \mathrm{mg}$ IV at day 1 every 6 weeks)

$\mathrm{N}=41$ treated with bevacizumab and irinotecan (340 or 125 $\mathrm{mg} / \mathrm{m} 2$ ) every 2 weeks (BI)

The median OS was 9 months (95\% Cl $0.0-$

18.8 months) and 5 months $(95 \% \mathrm{Cl} 4.2-5.8$ months) in the $\mathrm{BI}$ and PCV group respectively. The latter group had a worse toxicity profile grade III and IV.

At 1 year, $45.7 \%$ of patients in $\mathrm{BI}$ group were alive while only $0.1 \%$ was alive in the PCV group.

Authors conclusion:

$\mathrm{BI}$ seems a valuable treatment option in recurrent GBM with a good safety profile.

\section{Comments and Conclusions:}

Retrospective study as such classified as class III evidence.

Results:

Mack et

al (2014)

[23]
Study Description

Retrospective review of adult patients with recurrent glioma treated with BCNU

\section{Patient Population}

$\mathrm{N}=15$ adult patients with recurrent malignant glioma patients $(n=12$ recurrent $\mathrm{GBM})$

\section{Treatment}

All patients were treated with BCNU(130-150 mg/m2, day 1/42) and VM26 (45-60 $\mathrm{mg} / \mathrm{m} 2$, days 1-
III

Median PFS 2 months; median OS 4 months.

2 patients (14\%) developed grade $3 / 4$ hematologic toxicity

\section{Authors Conclusions:}

No beneficial effect was found.

Comments and Conclusions:

Very small retrospective study limiting any firm conclusions

$3 / 42)$

Santoni

et al

(2013)

[24] $\underline{\text { Results: }}$

Reasonably well tolerated. $15.3 \%$ grade $3-4$

thrombocytopenia and 9.2\% Grade 3-4 neutropenia.

Some evidence of activity: $1.5 \%$ CR, $18.5 \%$ PR, $27.7 \%$ SD. PFS6 35.4\%; OS 7.1 months.

\section{Authors conclusion:}

Fotemustine is a valuable therapeutic option for elderly glioblastoma patients, with a safe toxicity profile. 


\section{Treatment}

Patients were treated with fotemustine at 70-

$100 \mathrm{mg} / \mathrm{m} 2$ weekly for 3 weeks

and then every 3

weeks.

De Felice

et al

(2009)

[25]

\section{Comments and Conclusions:}

There appears to be some modest activity but the retrospective nature of the study limits firm conclusions

\section{Study Description}

Prospective Single-arm single institution study of patients with recurrent GBM treated with fotemustine

\section{$\underline{\text { Results: }}$}

III The median OS was 7.5 months from recurrence. No hematologic toxicity was

observed.

\section{Authors conclusion:}

Maintenance with low dose fotemustine approach could be considered a compromise treatment for patients with recurrent GBM.

\section{Patient Population}

$\mathrm{N}=8$ patients with recurrent GBM

\section{Treatment}

All patients received Fotemustine (induction 100 $\mathrm{mg} / \mathrm{m} 2$ followed by a maintenance $75 \mathrm{mg} / \mathrm{m} 2$ )

\section{Comments and Conclusions:}

Single arm study with only 8 patients during the maintenance period as such classified as

class III

\section{Table 3. Cytotoxic chemotherapy for PGBM patients: Other cytotoxic chemotherapy.}




\begin{tabular}{|c|c|c|c|}
\hline $\begin{array}{l}\text { Author } \\
\text { (year): }\end{array}$ & Description of study: & $\begin{array}{l}\text { Data } \\
\text { class: }\end{array}$ & Conclusions: \\
\hline \multirow{8}{*}{$\begin{array}{l}\text { Fiorentini } \\
\text { et al. } \\
(2019) \\
\text { [28] }\end{array}$} & Study_Description: & \multirow[t]{8}{*}{ III } & Results: \\
\hline & \multirow{2}{*}{$\begin{array}{l}\text { Multicenter retrospective } \\
\text { controlled study }\end{array}$} & & $\underline{\text { Tumor response and median overall survival }}$ \\
\hline & & & $\begin{array}{l}\text { Tumor response at the 3-month follow-up was observed in } 29 \% \\
\text { and } 48 \% \text { in pGBM and AST treated with mEHT compared to } 4 \% \\
\text { BSC. The median OS for mEHT was } 14 \text { months (range } 2-108 \\
\text { months). }\end{array}$ \\
\hline & \multirow{2}{*}{$\begin{array}{l}\text { Patient Population: } \\
\text { pGBM patients }(n=28) \\
\text { Astrocytomas }(A S T)(n= \\
\text { 24) }\end{array}$} & & Author's Conclusions: \\
\hline & & & $\begin{array}{l}\text { mEHT in integrative therapy may have a promising role in the } \\
\text { treatment and palliation of relapsed GBM and AST }\end{array}$ \\
\hline & \multirow{3}{*}{$\begin{array}{l}\text { Treatments: } \\
\text { modulated } \\
\text { electrohyperthermia } \\
\text { (mEHT) which combines } \\
\text { heat therapy and electric } \\
\text { field compared to best } \\
\text { supportive care (BSC). }\end{array}$} & & \\
\hline & & & Comments and Conclusions: \\
\hline & & & $\begin{array}{l}\text { Classified as Class III because study is retrospective } \\
\text { nonrandomized review. This study is limited by a low sample } \\
\text { size. and the small percentage of pGBM patients followed for } \\
\text { the 3- month tumor response. }\end{array}$ \\
\hline \multirow{9}{*}{$\begin{array}{l}\text { Silvani et } \\
\text { al (2019) } \\
\text { [29] }\end{array}$} & Study Description & \multirow[t]{9}{*}{ III } & Results: \\
\hline & \multirow{2}{*}{$\begin{array}{l}\text { Phase II trial of ortataxel } \\
\text { in adult recurrent GBM }\end{array}$} & & PFS- 6 was $11.4 \%$ \\
\hline & & & $\begin{array}{l}\text { 13.2\% of patients had grade III/IV neutropenia and } \\
\text { hepatotoxicity, } 15.8 \% \text { had grade III/IV leucopenia }\end{array}$ \\
\hline & \multicolumn{2}{|l|}{ Patient Population } & \\
\hline & \multirow{2}{*}{$\begin{array}{l}\mathrm{N}=40 \text { of adult patients } \\
\text { with recurrent GBM }\end{array}$} & & Authors conclusion: \\
\hline & & & $\begin{array}{l}\text { Ortataxel treatment failed to demonstrate significant activityin } \\
\text { recurrent GBM patients }\end{array}$ \\
\hline & \multicolumn{2}{|l|}{$\underline{\text { Treatments }}$} & \\
\hline & \multirow{2}{*}{$\begin{array}{l}\text { All patients were treated } \\
\text { with ortataxel } \\
\text { (75mg/m2 every } 3 \\
\text { weeks) }\end{array}$} & & Comments and Conclusions: \\
\hline & & & $\begin{array}{l}\text { Ortataxel was chosen because of preclinical data suggested } \\
\text { that it crossed the blood-brain barrier but since tumor drug } \\
\text { concentrations were not measured it is not clear if therapeutic } \\
\text { concentrations were achieved in the tumor. }\end{array}$ \\
\hline \multirow{6}{*}{$\begin{array}{l}\text { Jia et al. } \\
\text { (2015) } \\
\text { [30] }\end{array}$} & Study Description: & III & Results: \\
\hline & \multirow{2}{*}{$\begin{array}{l}\text { Single center prospective } \\
\text { phase I trial }\end{array}$} & & Safety and treatment response \\
\hline & & & $\begin{array}{l}\text { Skin erythema, cheilitis and conjuntivits was observed in Group } \\
4 \text {. Out of } 19 \mathrm{pGBM}, 5 \text { achieved minor response, } 6 \text { remained in } \\
\text { stable conditions, none achieve a partial or complete response. }\end{array}$ \\
\hline & \multirow{2}{*}{\multicolumn{2}{|c|}{$\begin{array}{l}\text { Patient Population: } \\
\text { pGBM }(n=19)\end{array}$}} & \\
\hline & & & Author's Conclusions. \\
\hline & $\begin{array}{l}\text { AA }(n=16) ; A O(n=4) ; \text { other } \\
(11)\end{array}$ & & The toxicities during RANT treatment were mild. \\
\hline
\end{tabular}


Treatments:

Retinoic acid naphthalene triazole (RANT) was administered in 4 different doses: Group 1, $50 \mathrm{mg} / \mathrm{sqm}(\mathrm{n}=5) ; \mathrm{G} 2$ $60 \mathrm{mg} / \mathrm{sqm}(\mathrm{n}=10) ; \mathrm{G} 3$ $80 \mathrm{mg} / \mathrm{sqm}(\mathrm{n}=30) ; \mathrm{G} 4$ $100 \mathrm{mg} / \mathrm{sqm}(\mathrm{n}=5)$.

\section{Comments and Conclusions:}

Classified as Class III because it is a phase I study. Since pGBM patients are dispersed among the four groups, the results reported above cannot be attributed to a specific dose.

$\begin{array}{ll}\begin{array}{l}\text { Roci et al } \\ \text { (2014) }\end{array} & \text { Study Description } \\ {[31]} & \begin{array}{l}\text { Retrospective study of } \\ \text { patients with high- } \\ \text { grade glioma }\end{array}\end{array}$

\section{Patient Population}

$\mathrm{N}=48$ high-grade glioma patients including $n=42$ patients with recurrent glioblastoma
III Results:

$28 \%$ at least minor response $49 \%$ stable disease

PFS-6 18\%

Median OS 7 months.

\section{Authors Conclusions:}

Single-agent carboplatin/cisplatin has modest activity in patients with recurrent HGG previously treated with one line of chemotherapy

\section{Comments and Conclusions:}

All patients were treated with carboplatin (AUC 57) or cisplatin 70 $\mathrm{mg} / \mathrm{m} 2$ every 4 weeks.

Minimal activity seen in this retrospective study with carboplatin or cisplatin

Rieger et al. (2014) [32]

\section{Study Description:}

Phase I open-label, prospective, single-arm study in 20 pGBM pts

\section{Patient Population:}

$\operatorname{pGBM}(n=20)$

\section{Treatments:}

Ketogenic diet which restricted carbohydrate intake to $60 \mathrm{~g} /$ day. Feasibility was the primary endpoint, secondary endpoints included the percentage of patients reaching urinary ketosis, progression-free survival (PFS) and overall survival (OS)

\section{Author's Conclusions:}

In conclusion, a ketogenic diet is feasible and safe but probably has no significant clinical activity when used as single agent in recurrent glioma

\section{Comments and Conclusions:}

Classified as Class III because it is a phase I study. 


\begin{tabular}{|c|c|c|c|}
\hline \multirow[t]{6}{*}{$\begin{array}{l}\text { Tonder et } \\
\text { al (2014) } \\
\text { [33] }\end{array}$} & $\begin{array}{l}\text { Study Description } \\
\text { Retrospective review of } \\
\text { patients with high grade } \\
\text { glioma heavily pre-- } \\
\text { treated }\end{array}$ & III & $\begin{array}{l}\text { Results: } \\
\text { Significant toxicity with Grade } 3 \text { - } \\
4 \text { hematologic toxicity in } 67 \% \text { of patients. }\end{array}$ \\
\hline & & & Median PFS was 2.5 months \\
\hline & Patient Population & & PFS6 was 0\% Authors' Conclusions: \\
\hline & $\begin{array}{l}\mathrm{N}=12 \text { heavily pretreated } \\
\text { adult patients with } \\
\text { recurrent high-grade } \\
\text { glioma } \mathrm{n}=8 \text { patients with } \\
\text { recurrent GBM }\end{array}$ & & $\begin{array}{l}\text { Carboplatin in combination with etoposide has an unfavorable } \\
\text { risk-benefit profile in heavily pre-treated glioma patients }\end{array}$ \\
\hline & Treatment & & \\
\hline & $\begin{array}{l}\text { All patients were treated } \\
\text { with } \\
\text { carboplatin }(240 \mathrm{mg} / \mathrm{m} 2 \\
\text { on day } 1) \text { and } \\
\text { etoposide }(100 \mathrm{mg} / \mathrm{m} 2 \text { on } \\
\text { days } 2 \\
\text { and } 3) \text { every } 4 \text { weeks }\end{array}$ & & $\begin{array}{l}\text { Comments and Conclusions: } \\
\text { Very small retrospective study showing no activity with } \\
\text { carboplatin and etoposide }\end{array}$ \\
\hline \multirow{9}{*}{$\begin{array}{l}\text { Da } \\
\text { Fonseca } \\
\text { et al. } \\
(2013) \\
{[34]}\end{array}$} & Study Description: & III & Results: \\
\hline & Single center Phase I/II & & Safety and treatment response \\
\hline & & & $\begin{array}{l}\text { POH caused occasional nose soreness }(5 / 198) \text { and rare } \\
\text { nosebleed }(2 / 198) \text {. }\end{array}$ \\
\hline & $\begin{array}{l}\text { Patient Population: } \\
\text { pGBM }(n=155) \text { pAA } \\
(n=27)\end{array}$ & & Author's Conclusions: \\
\hline & $\mathrm{pAO}(\mathrm{n}=16)$ & & $\begin{array}{l}\text { After } 4 \text { years, under exclusive } \mathrm{POH} \text { treatment, } 19 \% \text { of patients } \\
\text { remain in clinical remission. }\end{array}$ \\
\hline & Treatment: & & \\
\hline & Perillyl alcohol $(\mathrm{POH})$ & & Comments and Conclusions: \\
\hline & times daily started with & & Classified as Class III because it is a phase I/II study. \\
\hline & $\begin{array}{l}66.7 \mathrm{mg} / \mathrm{dose} ; 266 \\
\mathrm{mg} / \mathrm{day} \text { and escalated } \\
\text { up to } 133.4 \mathrm{mg} / \text { dose }\end{array}$ & & \\
\hline $\begin{array}{l}\text { Hu et al } \\
(2013)\end{array}$ & Study Description & III & Results: \\
\hline \multirow[t]{4}{*}{ [35] } & $\begin{array}{l}\text { Phase II prospective } \\
\text { study of patients with } \\
\text { recurrent GBM }\end{array}$ & & $\begin{array}{l}\text { Of } 25 \text { patients that the authors could analyze, only } 3(12 \%) \\
\text { reached PFS- } 6 \text {. }\end{array}$ \\
\hline & Patient Population & & Authors conclusion: \\
\hline & $\begin{array}{l}\mathrm{N}=29 \text { adult patients with } \\
\text { recurrent GBM }\end{array}$ & & $\begin{array}{l}\text { PFS- } 6 \text { in patients treated with the current regimen of gimatecan } \\
\text { at the time of recurrence was not significantly better than the }\end{array}$ \\
\hline & & & historical PFS- 6 for these patients. \\
\hline
\end{tabular}




\section{Treatment}

Patients were treated with gimatecan.

Treatment regimen was

Comments and Conclusions:

$1.0 \mathrm{mg} / \mathrm{m} 2 /$ day for 5

Single arm phase II study. Is a class III evidence because of no consecutive days during 28-day cycle for 12

cycles. comparison group. Gimatecan does not improve PFS when compared to historical data.

Table 4. Cytotoxic chemotherapy for pGBM patients: Tumor Treating Fields (TTF). 


\begin{tabular}{|c|c|c|c|}
\hline $\begin{array}{l}\text { Author } \\
\text { (year): }\end{array}$ & Description of study: & $\begin{array}{l}\text { Data } \\
\text { class: }\end{array}$ & Conclusions: \\
\hline \multirow{10}{*}{$\begin{array}{l}\text { Lu et al. } \\
\text { (2019) } \\
\text { [38] }\end{array}$} & \multirow{2}{*}{$\begin{array}{l}\text { Study Description: } \\
\text { Retrospective single } \\
\text { center study }\end{array}$} & \multirow[t]{10}{*}{ III } & Results: \\
\hline & & & $\underline{\text { Treatment response }}$ \\
\hline & \multirow{4}{*}{$\begin{array}{l}\text { Patient Population: } \\
\text { pGBM patients }(n=48) \\
\text { divided into } 2 \text { groups }\end{array}$} & & $\begin{array}{l}\text { OS and PFS for TBI+TTF were } 18.9 \text { and } 10.7 \text { months, } \\
\text { respectively, in comparison to BBC+TTF } 11.8(P>0.05) \text { and } 4.7\end{array}$ \\
\hline & & & $\begin{array}{l}\text { months, respectively. The median OS difference was } 14.7 \\
\text { months ( } 32.5 \text { vs. } 17.8 \text { ) }\end{array}$ \\
\hline & & & \\
\hline & & & Author's Conclusions: \\
\hline & \multirow{4}{*}{$\begin{array}{l}\text { Treatments: } \\
\mathrm{n}=30 \text { treated with } \\
\text { BBC+TTF } \mathrm{n}=18 \text { treated } \\
\text { by TBI+TTF }\end{array}$} & & $\begin{array}{l}\text { TBI regimen might play a role in the improvement of PFS and OS } \\
\text { in pGBM patients. }\end{array}$ \\
\hline & & & \\
\hline & & & Comments and Conclusions: \\
\hline & & & $\begin{array}{l}\text { Classified as Class III because study is a retrospective } \\
\text { nonrandomized review. }\end{array}$ \\
\hline \multirow{9}{*}{$\begin{array}{l}\text { Kezari } \\
\text { S. and } \\
\text { Ram Z. } \\
\text { (2017) } \\
{[39]}\end{array}$} & \multirow{3}{*}{$\begin{array}{l}\text { Study Description: } \\
\text { Post-hoc analysis of the } \\
\text { EF-14 trial }\end{array}$} & \multirow[t]{9}{*}{ III } & $\underline{\text { Results: }}$ \\
\hline & & & Safety and Treatment response \\
\hline & & & Median OS was significant longer than in the experimental group: \\
\hline & Patient Ponulation. & & 1.8 versus 9.2 months. No grade 3 or 4 toxicities were observed. \\
\hline & 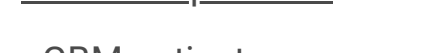 & & \\
\hline & pudivi patients & & Author's Conclusions: \\
\hline & \multirow{3}{*}{$\begin{array}{l}\text { Treatments: } \\
\mathrm{n}=144 \text { pts received TTF } \\
\text { plus chemo at first } \\
\text { recurrence after EF-14 } \\
\text { trial and } 60 \text { pts received } \\
\text { chemo alone (control } \\
\text { group) }\end{array}$} & & $\begin{array}{l}\text { TTF plus chemotherapy after first disease recurrence on TTF plus } \\
\text { TMZ or TMZ alone prolonged OS in patients in the EF- } 14 \text { trials } \\
\text { without added toxicity }\end{array}$ \\
\hline & & & Comments and Conclusions: \\
\hline & & & $\begin{array}{l}\text { Classified as Class III because it is a post-hoc analysis of a } \\
\text { phase III trial. }\end{array}$ \\
\hline \multirow{7}{*}{$\begin{array}{l}\text { Ansstas } \\
\text { and } \\
\text { Tran } \\
(2016) \\
{[40]}\end{array}$} & Study Description: & \multirow[t]{7}{*}{ III } & Results: \\
\hline & \multirow{2}{*}{$\begin{array}{l}\text { Prospective single center } \\
\text { case series }\end{array}$} & & $\underline{\text { Treatment response }}$ \\
\hline & & & $\begin{array}{l}\text { Median overall survival (OS) was } 216 \text { days ( } 7.2 \text { months). Median } \\
\text { OS from last dose of initial bevacizumab was } 237 \text { days ( } 7.9\end{array}$ \\
\hline & \multirow{2}{*}{$\begin{array}{l}\text { Patient Population: } \\
\text { pGBM }\end{array}$} & & $\begin{array}{l}\text { failures, and median OS from the first dose of bevacizumab } \\
\text { rechallenge was } 172 \text { days ( } 5.7 \text { months) }\end{array}$ \\
\hline & & & Author's Conclusions: \\
\hline & Treatments: & & $\begin{array}{l}\text { These results support the use of TTF therapy with pulse dose } \\
\text { bevacizumab as an option in patients with refractory GBM. }\end{array}$ \\
\hline & $\begin{array}{l}8 \text { pts with GBM on bev } \\
\text { with progressive disease } \\
\text { underwent }\end{array}$ & & Comments and Conclusions: \\
\hline
\end{tabular}


discontinuation of bev and treated with TTF.

Pulse bev was restarted at progression

Wong Study Description:

et al. Retrospective single

(2015) center study

[41]

\section{Patient Population:}

pGBM $(n=38)$ divided into

2 groups

Treatments:

$\mathrm{n}=3$ treated with TTF, bev

, and TCCC

$\mathrm{n}=35$ treated with TTF

and bev

Rulseh

et al

(2012)

[42]

Patient Population: GBM $(\mathrm{n}=20)$

Treatment: TTF
Classified as Class III because it is case series.

III Results:

Treatment response

A trend in prolonged OS was found for patients treated with NovoTTF, bev, and TCCC with median OS of 10.3 months compared to 4.1 in the other treatment group.

\section{Author's Conclusions:}

There is a possibility to improve survival by adding TCCC in pGBM patients.

\section{Comments and Conclusions:}

Classified as Class III because it is retrospective review.

Results:

\section{Treatment response}

2 pts with pGBM were alive in good health and no longer receiving any treatment more than seven years after initiating TTF therapy, with no clinical or radiological evidence of recurrence.

\section{Author's Conclusions:}

Our results indicate that TTF treatment may be remarkably successful in a subgroup of GBM/RGBM patients, and further investigation is needed to identify any unique characteristics of this patient group.

\section{Comments and Conclusions:}

Classified as Class III because it is a pliot study.

$\begin{array}{ll}\text { Stupp } & \text { Study Description: } \\ \text { et al } & \\ \text { (2012) } & \text { Multi-center randomized } \\ & \text { phase III trial }\end{array}$

[43]

II $\quad \underline{\text { Results }}$

\section{Safety and Treatment response}

Median OS was 6.6 versus 6.0 months, 1 -year survival rate was $20 \%$ and $20 \%$, progression-free survival rate at 6 months was $21.4 \%$ and $15.1 \%(p=0.13)$, respectively in TTF and active control patients. Severe adverse events occurred in $6 \%$ and $16 \%$ $(p=0.022)$ of patients treated with TTF and chemotherapy, respectively.

\section{Author's Conclusions:}

Treatments: chemotherapy-free treatment with NovoTTF
No improvement in OS was demonstrated, however efficacy and activity with this chemotherapy-free treatment device appears comparable to chemotherapy regimens that are commonly used for recurrent glioblastoma. Toxicity and quality of life clearly favoured TTF. 
$(20-24$ h/day) $(n=120)$

versus

active chemotherapy

$(n=117)$

Comments and Conclusions:

Classified as Class II because it is a phase III trial

Abbreviations: BBC= Bevacizumab-based chemotherapy, Bev= Bevacizumab, TCCC= 6-thioguanine [80 mg/m2 every 6 hour from days 1 to 3] lomustine [100 mg/m2on day 4] capecitabine [825 mg/m2 every 12 hour from day 5] celecoxib $400 \mathrm{mg}$ every 12 hour from days 11 to 24 . The cycle is repeated every 42 days or 6 weeks. All meds are oral.],TBI= TMZ, Bev, irinotecan, TTF= Tumor Treating Fields.

Table 5. Cytotoxic chemotherapy for pGBM patients: oncolyticvirotherapy. 


\begin{tabular}{|lll}
\hline $\begin{array}{l}\text { Author } \\
\text { (year): }\end{array}$ & Description of study: & $\begin{array}{l}\text { Data } \\
\text { class: }\end{array}$
\end{tabular}

Lang et al. Study_Description: III Results:

(2018) Single center phase I trial

\section{Toxicity, Survival and tumor effects}

No dose-limiting toxicities were observed in the study. $20 \%$ of patients survived $>3$ years from treatment, and three patients

Patient Population:

$\operatorname{pGBM}(n=37)$ had $a=95 \%$ reduction in the enhancing tumor $(12 \%)$, with all three of these dramatic responses resulting in $>3$ years of progression-free survival from the time of treatment. Direct virus-induced oncolysis was documented

\section{Treatments:}

Oncolytic adenovirus

DNX-2401 (Delta-24-RGD; tasadenoturev) Phase I A Dose-escalation with 8 dose levels in 25 pts; Phase IB permanent catheter with intratumoral injection followed by resection 14 days later in 12 pts.

\section{Author's Conclusions:}

Treatment with DNX-2401 resulted in dramatic responses with long-term survival in recurrent high-grade gliomas that are probably due to direct oncolytic effects of the virus followed by elicitation of an immune-mediated anti-glioma response

Comments and Conclusions:

Classified as Class III because it is a phase I trial.

$\begin{array}{ll}\begin{array}{l}\text { Geletneky } \\ \text { et al }\end{array} & \text { Study Description: } \\ (2017) & \text { Multi- center Phase I/Ila } \\ & \text { (ParvOryx01 trial) }\end{array}$

[45]

Patient Population: $\operatorname{pGBM}(n=18)$

\section{Treatments:}

Oncolytic $\mathrm{H}-1$ Parvovirus (H-1PV) Arm 1: the first dose of $\mathrm{H}-1 \mathrm{PV}$ was injected intratumorally. Arm 2: five intravenous virus infusions on days $1-5$. On day 10 , all patients of both arms underwent tumor resection, and virus was re-injected around the resection cavity.
III Results:

\section{Toxicity, Progression free survival, Overall Survival}

$\mathrm{H}-1 \mathrm{PV}$ treatment showed no dose-dependent side effects or dose- limiting toxicity (DLT). PFS at 6 months was 27\%, and median PFS was 111 days. OS was 72\%, and median OS was 464 days.

\section{Author's Conclusions:}

Altogether, $\mathrm{H}-1 \mathrm{PV}$ results provide an impetus for further $\mathrm{H}-1 \mathrm{PV}$ clinical development.

\section{Comments and Conclusions:}

Classified as Class III because it is a phase I/II trial.

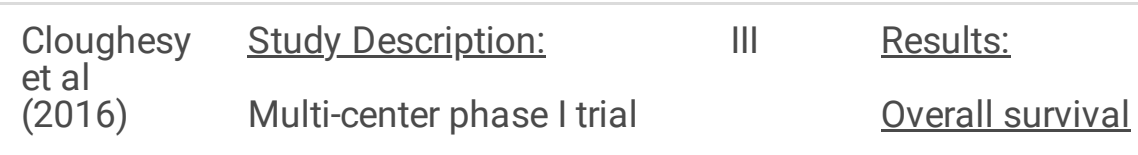

\section{[46]}

Patient Population:

OS was 13.6 months and was statistically improved relative to external control.

High grade gliomas

(HGG) including pGBM

\section{Author's Conclusions:}


$(n=45)$

\section{Treatment:}

Toca 511 (vocimagene amiretrorepvec) a oncolytic, retroviral replicating vector (RRV) that delivers a yeast cytosine deaminase, which converts subsequently administered courses of the prodrug Toca FC (extended-release 5fluorocytosine) into the antimetabolite 5-

fluorouracil causing oncolytic effects.

et al

(2014)

[47]

Multi-center phase I study

(REOLYSIN trial)

Patient Population: pGBM

$(n=12)$

High grade gliomas $(n=3)$

Treatment:

Reovirus Dose escalation study ranging from $1 \times$ $10(8)$ to $1 \times 10(10)$ tissue culture infectious dose 50 , ten times the dose achieved in Forsyth et

al (2008)

\section{Markert et Study Description: Single III} al (2009) center phase I trial

[48]
The favorable assessment of Toca 511 and Toca FC supports confirmation in a randomized phase $2 / 3$ trial (NCT02414165).

\section{Comments and Conclusions:}

Classified as Class III because study is a phase I trial

III $\underline{\text { Results: }}$

Toxicity, Maximum tolerated dose (MTD),

There was 1 grade 3 adverse event (seizure), no grade 4. MTD was not achieved.

Author's Conclusions:

The intratumoral infusion of reovirus in patients with recurrent malignant glioma demonstrated the approach to be safe and well tolerated, warranting further studies.

Comments and Conclusions:

Classified as Class III because study is a phase I trial

$$
\frac{\text { Patient }}{(n=6)}
$$

\section{Comments and Conclusions:}

Classified as Class III because study is a phase I trial

\section{Treatment:}

G207, a doubly mutated

(deletion of both y134.5

loci, insertional

inactivation of UL39)

herpes simplex virus

(HSV) was

stereotactically inoculated 
with total two doses of

totaling to $1.15 \times$

109 plaque-forming units

Forsyth et Study Description: Single III al (2008) center phase I trial

[49]

\section{Patient Population:}

Recurrent high-grade gliomas $(n=12 ; 9 / 12$ pGBM)

\section{Treatment:}

intratumoral administration of reovirus with escalating doses (3pts/dose).

Results:

Toxicity, Maximum tolerated dose (MTD), Time-to-progression (TTP).

There were no grade III or IV adverse events (AEs). MDP was not reached. Median TTP was 4.3 weeks (range, 2.6-39).

Ten patients had tumor progression, one had stabilization, and one was not evaluable for response. Median survival was 21 weeks (range, 6-234), and one is alive 54 months after treatment.

\section{Author's Conclusions:}

The intratumoral administration of the genetically unmodified reovirus was well tolerated using these doses and schedule, in patients with recurrent high grade gliomas.

Comments and Conclusions:

Classified as Class III because study is a phase I trial

Freeman Study Description: III Results:

et al

(2006)

Single center phase I/II

[50] trial

Toxicity, Maximum tolerated dose (MTD), Time-to-progression (TTP), overall survival ( $\underline{\text { OS }}$.

Toxicity was minimal with Grade I/II constitutional fever being seen in 5 patients. MTD was not achieved. TTP ranged from 2 to 37 weeks. OS ranged from 3 to 66 weeks. Anti-NDV

Patient Population: pGBM $(n=13)$ hemagglutinin antibodies appeared within 5-29 days. NDVHUJ was recovered from blood, saliva, and urine samples and one tumor biopsy.

Treatment:

Author's Conclusions:

Intravenous New Castle Disease virus strands HUJ

(NDV-HUJ) oncolytic virus

The findings of good tolerability and encouraging responses warrant the continued evaluation of NDV-HUJ in GBM Comments and Conclusions:

Classified as Class III because study is a phase I trial

Chiocca et Study Description: III Results:

al (2004)

[51]

Multi-center center phase I

(ONYX-015)

Toxicity, Maximum tolerated dose (MTD), Time-to-progression (TTP)

There were no serious adverse events (AEs). MTD was not achieved. The TTP after treatment with ONYX-015 was 46 days (range 13-452). The median survival time was 6.2 months (range

High-grade glioma, including pGBM $(n=24)$

1.3 -28.0 + months). Injection of ONYX-015 into glioma cavities is well tolerated at doses up to 10(10) pfu.
Treatment:

Intra-tumor cavity

injection of ONYX-015, an
Author's Conclusions:

Page $43 / 46$ 
adenovirus mutant that is thought to replicate more efficiently in cells with disruptions in the p53 tumor suppressor pathway (such as tumor cells)
Injection of ONYX-015 into glioma cavities is well tolerated at doses up to 10(10) pfu.

Comments and Conclusions:

Classified as Class III because study is a phase I trial

Table 6. Cytotoxic chemotherapy for PGBM patients: Quality of Life QO 


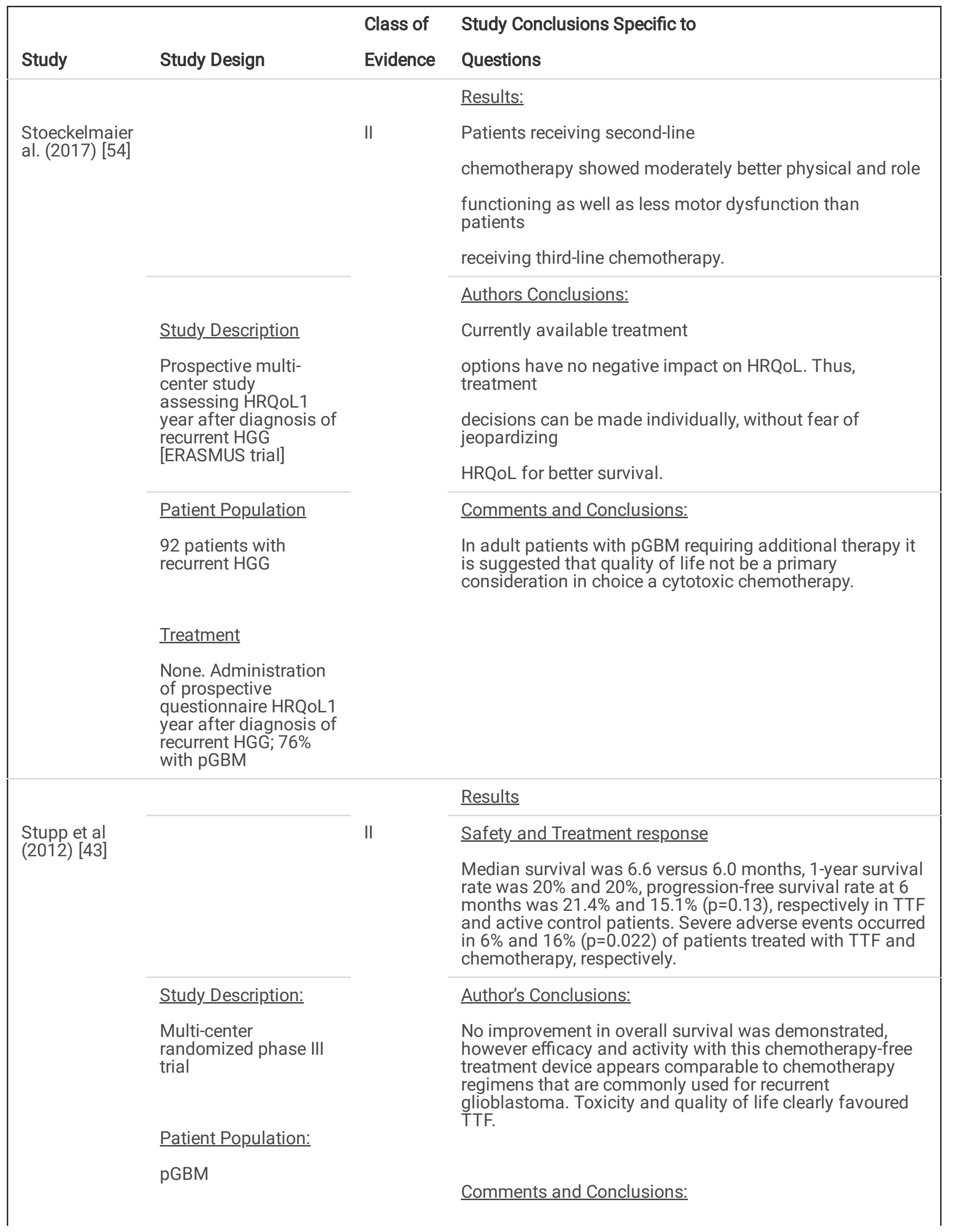


chemotherapy-free

treatment with

NovoTTF (20-

24 h/day) ( $n=120)$

versus active

chemotherapy

$(n=117)$

\section{Figures}

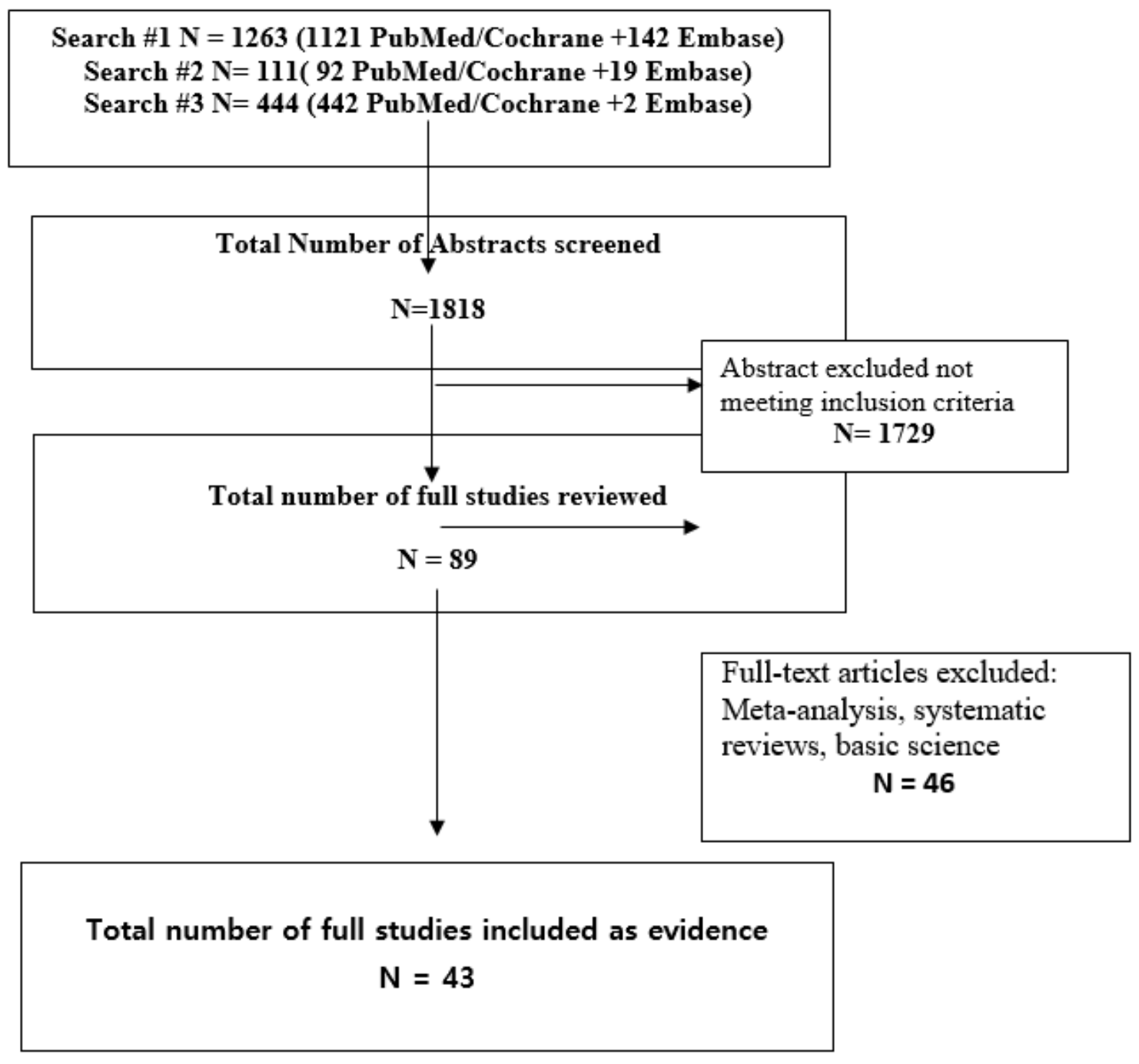

Figure 1

PRISMA Flow Chart 